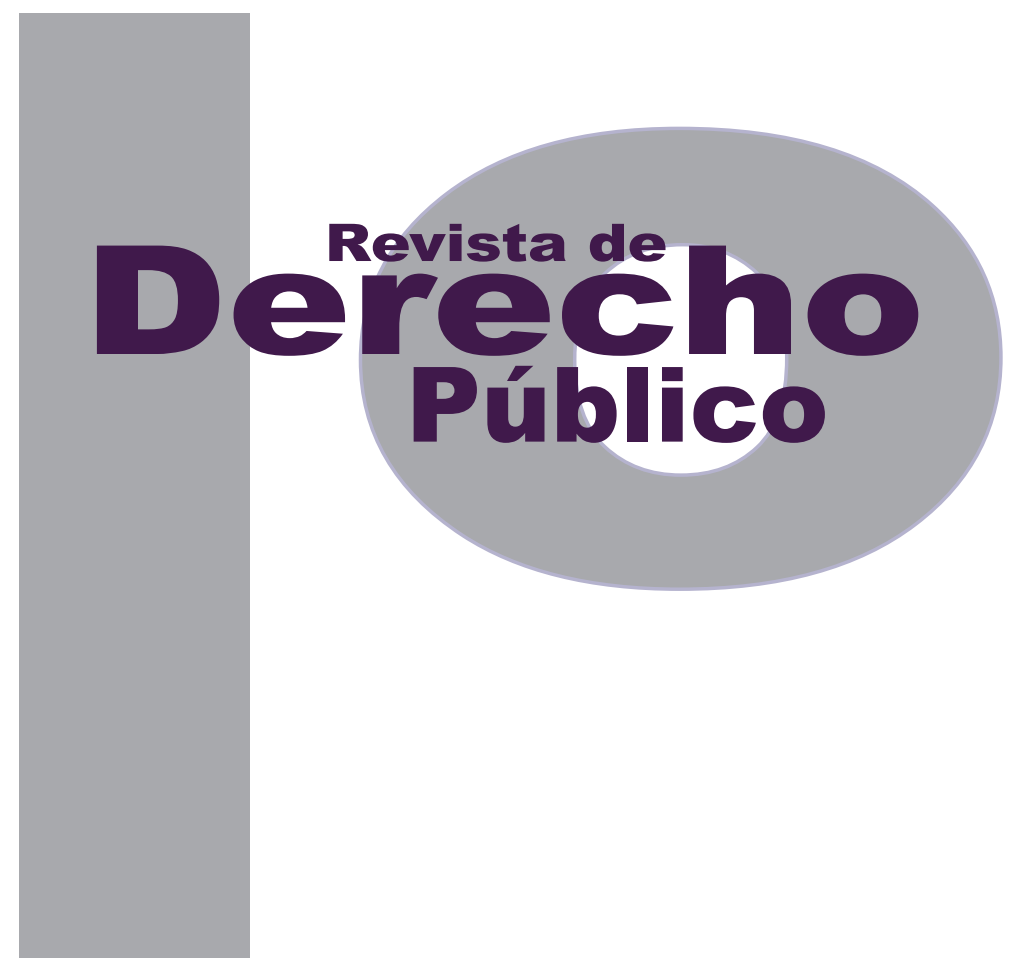

\title{
LESIONES PERSONALES CAUSADAS CON ÁCIDOS, ÁLCALIS, SUSTANCIAS SIMILARES O CORROSIVAS, UNA REFORMA DEL 2013
}

\author{
Carlos Gónima díaz Granados
}

DOI: http://dx.doi.org/10.15425/redepub.33.2014.05

Universidad de los Andes

Facultad de Derecho

Revista de Derecho Público N. ${ }^{\circ} 33$

Julio - Diciembre de 2014. ISSN 1909-7778 


\title{
Lesiones personales causadas con ácidos, álcalis, sustancias similares o corrosivas, una reforma del 2013
}

\section{Resumen}

Este trabajo presenta el estudio sobre las causas que justificaron la creación del nuevo tipo penal de lesiones personales que producen deformidad por medio del uso de ácidos, álcalis, sustancias corrosivas o sustancias similares y las implicaciones de esta modificación jurídica. Se realizó a partir del contraste entre la nueva figura jurídica colombiana, sus pares en el escenario internacional, las cifras de afectados con estas sustancias en Colombia y la doctrina penal en materia de lesiones personales que causan deformidad. Algunos de los resultados más importantes son que el nuevo tipo penal sanciona la agresión en virtud de los medios empleados y no exclusivamente en virtud del resultado material, tal y como lo hacen el resto de tipos de lesiones personales en el ordenamiento colombiano y, por otra parte, que el tipo penal sanciona un mayor desvalor de acción objetiva pero no necesariamente hay un mayor desvalor de resultado en comparación con otros tipos de lesiones personales (deformidades) no causadas con estos medios.

Palabras clave: bien jurídico, lesiones personales, deformidad, ácidos, álcalis, sustancias corrosivas, tipo penal, desvalor de acción objetivo, desvalor de resultado, prevención general negativa.

\section{Personal injuries caused with acids, alkalis, corrosive or similar substances, a legal reform made in 2013}

\begin{abstract}
This work is a study on the causes that justified the creation of the new offense of causing personal injury deformity by the use of acids, alkalis, corrosive substances or similar substances and the legal implications of this modification. The study was conducted from the contrast between the new Colombian legal figure, it's peers in the international arena, the numbers of people affected with these substances in Colombia and the criminal doctrine for personal injury that causes deformity. Some of the most important results are that the new offense punishes not only the material result (deformitydisfiguration of the victim) but also imposes a sanction for the means utilized to cause the result, however the Colombian criminal code used to sanction personal injuries solely on the basis of the result, now, this does not entail that injuries caused by this kind of means are ipso facto more harmful than the deformities caused by other type of instruments.
\end{abstract}

Keywords: personal injuries, deformity, acids, alkalis, corrosive substances, criminal offense.

\section{Lesões pessoais causadas por ácidos, álcalis, substâncias similares ou corrosivas, uma reforma de 2013}

\section{Resumo}

Este trabalho apresenta o estudo sobre as causas que justificaram a criação do novo tipo penal de lesões pessoais que produzem deformidade por meio do uso de ácidos, álcalis, substâncias corrosivas ou substâncias similares e as implicações desta modificação jurídica. Foi realizado a partir do contraste entre a nova figura jurídica colombiana, seus pares no cenário internacional, as cifras de afetados com estas substâncias na Colômbia e a doutrina penal em matéria de lesões pessoais que causam deformidade. Alguns dos resultados mais importantes são que o novo tipo penal sanciona a agressão em virtude dos meios empregados e não exclusivamente em virtude do resultado material, tal e como o fazem o resto de tipos de lesões pessoais no ordenamento colombiano e, por outra parte, que o tipo penal sanciona um maior desvalorização de ação objetiva mas não necessariamente há uma maior desvalorização de resultado em comparação com outros tipos de lesões pessoais (deformidades) não causadas por estes meios.

Palavras-chave: bem jurídico, lesões pessoais, deformidade, ácidos, álcalis, substâncias corrosivas, tipo penal, desvalorização de ação objetivo, desvalorização de resultado, prevenção geral negativa. 


\title{
Lesiones personales causadas con ácidos, álcalis, sustancias similares o corrosivas, una reforma del 2013*
}

\section{Carlos Gónima Díaz Granados**}

\begin{abstract}
Las quemaduras por los ácidos son frecuentemente accidentales, ya se trate por obreros de las fábricas de productos químicos sorprendidos por la ruptura de un recipiente que contenga un ácido, ya, por el contrario, se trate de un niño que vierta ácido sobre sí dejado a su alcance. Sin embargo, no son tampoco excepcionales, desgraciadamente, los atentados criminales que consisten en desfigurar al amante infiel, al seductor, o a la rival, proyectando en su cara ácido corrosivo,
\end{abstract} especialmente ácido sulfúrico (Gutiérrez, 1952, p. 186).

\section{SUMARIO}

Introducción - I. LA FORMACIÓN JURÍDICA: UNA APROXIMACIÓN AL PROBLEMA - A. El origen de la figura jurídica - B. En Colombia: la reforma y sus números - II. EL DELITO - A. El bien jurídico - B. El sistema de lesiones personales en Colombia - C. Análisis del tipo penal - 1. La deformidad - 2. El tipo penal - 3. Aspecto objetivo del tipo penal - a) Sujetos - b) Objeto jurídico y objeto sobre el cual recae la acción - c) Verbo rector único de conducta específica - d) Los medios - e) El resultado en el tiempo ¿le aplican las secuelas transitorias o permanentes al nuevo tipo penal? - f) La tentativa - 4. Aspecto subjetivo del tipo penal - a) Dolo - b) Culpa - c) Otras hipótesis - D. Análisis de punibilidad - 1. La cláusula de absorción - 2. Los agravantes específicos - a) El artículo 119 del cP - b) Numeral 4, artículo 104 cP: “Por precio, promesa remuneratoria, ánimo de lucro o motivo abyecto o fútil” - c) Numeral 6, artículo 104 cP: "con sevicia” - d) Numeral 7, artículo 104 cp: "Colocando a la víctima en situación de indefensión o inferioridad o aprovechándose" - 3. Los agravantes genéricos y los cuartos de movilidad punitiva - a) Numeral 3, artículo 58 cP: “Que la ejecución de la conducta punible esté inspirada en móviles de intolerancia y discriminación referidos a la raza, la etnia, la ideología, la religión, o las creencias, sexo u orientación sexual o alguna enfermedad o minusvalía de la víctima” - b) Numeral 4, artículo 58 cP: "emplear en la ejecución de la conducta medios de cuyo uso pueda resultar peligro común” - III. CONCLUSIONES - Referencias.

* Cómo citar este artículo: Gónima Díaz Granados, C. (Diciembre, 2014). Lesiones personales causadas con ácidos, álcalis, sustancias similares o corrosivas, una reforma del 2013. Revista de Derecho Público, 33. Universidad de los Andes (Colombia).

** Abogado de la Universidad de los Andes y estudiante de la especialización en Derecho Penal de la Universidad Sergio Arboleda. Correo: carlos.gonima. dzg@gmail.com 
Introducción

En el año 2013 el Congreso de la República de Colombia aprobó la Ley 1639 por medio de la cual se busca "fortalecer las medidas de prevención, protección y atención integral a las víctimas de crímenes con ácido, álcalis o sustancias similares o corrosivas que generen daño o destrucción al entrar en contacto con el tejido humano" (art. 1). Esta Ley, que consta de seis artículos, busca controlar el comercio de sustancias corrosivas (principalmente ácidos o álcalis), priorizar la atención y el tratamiento médico para las víctimas de estos ataques y, por último, modificó el artículo 113 del Código Penal (cP).

Este trabajo estudiará la modificación legislativa del artículo 113 del CP, precepto legal que ha sido el epicentro de una controversia mediática muy importante en los últimos meses. Desde sus inicios en el Congreso hasta el día de hoy, el tema ha enfrentado a los representantes de las instituciones más importantes del país y, como era de esperarse, algunas de las posturas son mucho más acertadas y deseables que otras.

Durante los debates preliminares a su aprobación en el Congreso, mientras uno de los ponentes insistía, de manera equivocada a nuestro juicio, en que el ordenamiento jurídico colombiano no contaba con una figura jurídico penal que sancionara a los sujetos activos de esta modalidad delictiva, ${ }^{1}$ otro ponente, igual de equivo-

"indiferencia e indolencia se evidencian en nuestra legislación como expresión colectiva de la sociedad, por lo que tampoco ha contemplado estas acciones como delitos contundentemente tipificados" (Pro- cado que el anterior, afirmaba que el problema no radicaba en la atipicidad de la conducta sino en que las lesiones derivadas de estos ataques únicamente podían ser catalogadas como lesiones simples y no complejas. ${ }^{2}$

A su turno, la Procuraduría General de la Nación (en cabeza del procurador general Alejandro Ordóñez) expresó públicamente que esta modalidad delictiva no era una manifestación propia del delito de lesiones personales sino del delito de tortura (Semana.com, 10 de abril de 2014). De forma similar han opinado algunos senadores de la República, quienes consideran que el delito no solo debería ser tipificado como tortura física sino psicológica y, además, como un crimen de lesa humanidad (Semana.com, 9 de abril de 2014). En igual sentido se pronunció el vicefiscal general de la Nación, Jorge Perdomo, quien consideró que esta clase de comportamientos se podrían tipificar como una tentativa de homicidio doloso o una tortura según el daño causado al sujeto pasivo (Semana.com, 9 de abril de 2014).

En la orilla opuesta, con un planteamiento más preciso, el entonces ministro de Justicia, Alfonso Gómez Méndez, afirmó que este tipo de propuestas se inscriben dentro de una política criminal coyuntural, lo que es completamente indesea-

yecto de Ley 091 de 2011 Cámara. Gaceta del Congreso, XX(678), 12 de septiembre de 2011, p. 19).

2 "el presente proyecto de ley contempla una adhesión al condigo (sic) penal vigente, buscando que se tipifique expresamente el ataque con ácido como un delito, desligándolo a la simple lesión personal, que a su vez está sujeta a los días de incapacidad para medir la gravedad de la pena" (Informe de ponencia para primer debate al Proyecto de Ley 239 de 2012 Senado, 091 de 2011 Cámara. Gaceta del Congreso, XXI(536), 21 de agosto de 2012, p. 5). 
ble. Además, señaló que el aumento de penas no es sinónimo de prevención general negativa y que era imperativo enfocar los esfuerzos en tener una persecución penal eficiente (Semana. com, 9 de abril de 2014).

Como es evidente, este delito ha despertado opiniones encontradas en todas las ramas del poder colombiano, cuestión que genera cierta inseguridad jurídica y nos lleva a preguntarnos: ¿quién tiene la razón?, ¿a qué título se deben imputar los ataques con ácidos?, ¿si no se aplica el nuevo tipo penal autónomo, entonces para qué se creó un tipo autónomo?, ¿realmente es aplicable este tipo penal autónomo?

Al margen de esta discusión político criminal se encuentran las víctimas y el nuevo tipo penal. En cuanto a las víctimas, lo cierto es que las cifras son poco alentadoras y demuestran, como se verá más adelante, que la violencia con ácidos es un fenómeno al que sí es necesario prestarle atención y que resulta imperativo establecer un mecanismo único para atender esta problemática. Frente al nuevo precepto legal, que suponía ser la panacea e iba a eliminar esta modalidad delictiva, cabe advertir que no es tenido en cuenta ni siquiera por la Fiscalía General de la Nación, a menos de un año después de haber entrado en vigor.

De manera que tanto la polémica como la incertidumbre han puesto a este delito en el foco de atención de los medios de comunicación, convirtiéndolo en un tema actual e importante que merece la pena ser estudiado en profundidad.
Teniendo en cuenta lo anterior, en este texto se analizarán a fondo las características dogmáticas del nuevo tipo penal autónomo. En este orden de ideas, este partirá de la descripción del origen del tipo penal en el escenario internacional e, inmediatamente después, tratará su creación en el ordenamiento colombiano. Ambos temas serán tratados en el primer capítulo.

En el segundo capítulo se abordarán los aspectos relativos a la figura penal y sus repercusiones en el ámbito del derecho: i) el bien jurídico tutelado, ii) una aproximación al tratamiento que el legislador le ha dado a las lesiones personales en Colombia, iii) el aspecto objetivo del tipo penal, iv) el aspecto subjetivo del tipo penal, v) las repercusiones positivas que tiene la modificación en sede de tentativa y vi) un análisis de la punibilidad del nuevo tipo penal. Por último, se expondrán las conclusiones sobre el tema.

\section{LA FORMACIÓN JURÍDICA: UNA APROXIMACIÓN AL PROBLEMA}

\section{A. El origen de la figura jurídica}

La protección de las deformidades causadas con ácidos, álcalis, sustancias corrosivas o similares, previstas como tipo penal en la legislación vigente, no es originaria de Colombia, por lo menos no como un tipo autónomo independiente. Precisamente, como señala Fernando Velázquez (2013a): "Esta figura no tiene antecedentes en el derecho positivo ni tampoco se suele encontrar en los códigos penales de las naciones que se alinean en esta órbita cultural 
(...) estos atentados aparecen en la legislación penal de Bangladesh y se anuncian en las legislaciones de Camboya y Pakistán" (pp. 252, 253).

Lo cierto es que el epicentro de la necesidad de tipificar esta especial y muy particular forma de lesiones personales complejas como delito es Bangladesh. De hecho, de acuerdo con Shah (2009) "en el año 2002, cerca de 280 mujeres pakistaníes fueron asesinadas y otras 750 fueron lesionadas debido a la violencia con ácidos" (p. 1172), ${ }^{3}$ año en el cual la autoridad legislativa de Bangladesh promulgó la ley por medio de la cual se creó el tipo autónomo de lesiones causadas con ácidos (p. 1175). ${ }^{4}$

Ahora bien, cabe señalar que los ataques con ácidos en países como Bangladesh o la India tienen un móvil bastante particular. Estos constituyen una de las múltiples modalidades de violencia por medio de la que se materializan los crímenes de honor (De Silva de Alwis, 2012, p. 181). Así las cosas, lo que determina al sujeto activo a cometer el ataque, en muchos de los casos, es el rechazo a la propuesta matrimonial o el rechazo al acercamiento sexual por parte de la víctima (Shah, 2009, p. 1173). Por si fuera poco, los sujetos pasivos de los ataques con ácidos en estos países son, de forma predominante, las mujeres. En consecuencia, es evidente el

3 Traducción realizada por mí.

4 Dicha ley persigue las siguientes finalidades: i) establecer el tipo penal de lesiones personales causadas con ácidos en el Código Penal, ii) establecer una pena clara para dicho delito, iii) perseguir el delito como una ofensa criminal, iv) regular el comercio de ácidos y v) capacitar a las autoridades policiales en cómo se debe reaccionar en un eventual ataque con ácidos (p. 1175). hecho de que allí esta fenomenología criminal "no pueda ser interpretada como una especie de meros 'hechos brutos' aislados e individualizados, sino que, por el contrario, ha de ser interpretada en clave política, esto es, en clave de reconocimiento de un 'sistema' que instituye estructuras de relaciones injustas de poder (...) en forma de violencia" (Barreré, 2009, p. 15), lo que permite catalogar a esta modalidad delictiva como un delito de género. En suma, la mezcla entre el móvil, la ‘justificación’ cultural, los abrumadores índices de violencia con una afectación particular al género femenino y el medio empleado para cometer este delito es lo que lleva a clasificarlo como violencia en contra de las mujeres.

Es más, en el año 2001 la comunidad académica ya había llamado la atención de la comunidad internacional y exhortó tanto a Bangladesh como a la India a promulgar leyes tendientes a proteger los derechos de las víctimas de delitos basados en discriminación de género (Taylor, 2001, p. 423). En este mismo sentido han opinado las Naciones Unidas, organización que en el año 2009 emitió una guía de sugerencias legislativas para desincentivar la violencia de género en contra de las mujeres. En el marco de esa guía de sugerencias, se instó a todos los miembros de dicha organización a criminalizar los ataques con ácidos como un delito autónomo y a tomar como modelo las leyes emitidas en Bangladesh (Naciones Unidas, 2009, pp. 22 y 23).

Sin embargo, es importante resaltar que no fue propiamente la atipicidad de la conducta lo que motivó a países como Bangladesh o Pakistán 
a considerar la creación de este marco legal. Según Shah (2009) una confluencia de factores determinaron esta necesidad, entre ellos: i) la existencia de multiplicidad de jurisdicciones que impedía la eficiente persecución y judicialización de los ataques con ácidos (p. 1176), ii) el que era un delito desistible y iii) los altos índices de impunidad que agobiaban a estas sociedades (pp. 1188 y 1189).

En síntesis, se puede afirmar que este es un fenómeno que se presenta de manera predominante en algunos países del sur y sudeste asiático, y que hasta hace poco era, como se ve, extraño para las sociedades de Occidente (De Silva de Alwis, 2010, p. 18). Así mismo, en estos países asiáticos los ataques con estas sustancias corrosivas no se caracterizan únicamente por el resultado material, la deformidad, sino que tienen un antecedente social y cultural importante: la jerarquía social como fundamento de los delitos de honor, que le otorga a esta conducta punible la connotación de delito de género.

\section{B. En Colombia: Ia reforma y sus números}

En septiembre de 2011 inició el curso legislativo del Proyecto de Ley 091 en la Cámara de Representantes, el cual se convirtió, a la postre, en la Ley 1639 de 2013. A lo largo de los debates se presentaron posiciones que merecen la pena ser resaltadas dado que, en esencia, fueron estas las que determinaron la reforma legislativa.

En primer lugar, varios de los ponentes consideraron que la creación de un nuevo tipo penal era imperativo debido a que no existía, para ese entonces, una figura jurídica que sancionara 'contundentemente' los ataques con ácidos (Proyecto de Ley 091 de 2011 Cámara, p. 19). Posteriormente, otro ponente creyó necesario el delito, dado que los ataques con ácidos solo podían ser imputados a título de lesiones simples y no complejas (Informe de ponencia para primer debate al Proyecto de Ley 239 de 2012 Senado, 091 de 2011 Cámara, p. 5). La verdad es que a ninguno de los dos ponentes le asistió la razón. Para el momento en que este proyecto de ley se encontraba en trámite legislativo, todos los ataques con ácidos que hubieran causado deformidades eran conductas punibles a la luz del artículo 113 cP (lesiones complejas por deformidad). Lo que sí es cierto es que antes de la modificación legislativa los medios empleados para causar la deformidad eran completamente extratípicos para el artículo 113 del cP, pero no lo eran, como veremos más adelante, ni para las circunstancias de agravación punitiva específicas (artículos 119 y 104 cP), ni para las circunstancias de agravación punitiva genéricas (artículo 58 cP). Por ello, la deformidad, al igual que las otras clases de lesiones personales, únicamente se calificaban jurídico-penalmente por un resultado material (las secuelas) y no por los medios empleados.

En segundo lugar, a lo largo del proceso legislativo los ponentes concibieron los ataques con ácidos o sustancias similares como una modalidad delictiva de género. Así quedó plasmado en una de las ponencias, donde se afirmó que “cada día más, nuestra sociedad se ve afectada por delitos atroces que atentan contra la vida y la 
integridad de las personas, en especial mujeres indefensas o que bajo el factor sorpresa son víctimas" (Proyecto de Ley 091 de 2011 Cámara, p. 19, cursivas fuera del texto original). De la mano de esta posición se anexaron las estadísticas de violencia interpersonal por quemaduras con agentes químicos o sólidos calientes, del Instituto Nacional de Medicina Legal (INML), vigentes para el momento de la ponencia (junio de 2011). Lo curioso es que dichas cifras establecen un patrón particularmente diferente al que mencionó el ponente, de hecho, indican que entre el año 2007 y junio del 2011 hubo un total de 730 lesionados, con agente químico o sólido caliente, en el cuello o en el rostro; de estos 437 fueron hombres y 293 fueron mujeres. ${ }^{5}$ Así mismo, estas cifras no solo apuntan en la dirección contraria a la afirmación realizada por el ponente, sino que, adicionalmente, no son concluyentes para acreditar la necesidad de la reforma jurídica. Lo anterior se debe a que las estadísticas abarcan tanto quemaduras con agentes químicos como quemaduras con sólidos calientes, lo cual implica la inclusión, por ejemplo, de quemaduras con instrumentos de uso doméstico tales como planchas, elementos que son completamente ajenos a la modificación legislativa y no sustentan de manera adecuada la necesidad del nuevo tipo penal autónomo.

5 Instituto Nacional de Medicina Legal y Ciencias Forenses - Grupo Centro de Referencia Nacional sobre Violencia. Sistema de información para el análisis de la violencia y la accidentalidad en Colombia -SIAVAC. Los datos de estas estadísticas están divididos entre lesiones en el cuello o faciales y por género del sujeto pasivo. Vale aclarar que las cifras no incluyen lesiones en otras partes del cuerpo diferentes al cuello y a la cara y cubren del 2007 a junio de 2011: I) 2007: 88 hombres y 75 mujeres. II) 2008: 84 hombres y 61 mujeres. III) 2009: 103 hombres y 71 mujeres. IV) 2010: 116 hombres y 57 mujeres. V) 2011: 46 hombres y 29 mujeres (Proyecto de Ley 091 de 2011 Cámara, p. 24 y ss.).
Posteriores estadísticas del INML (2013) indican que entre el año 2010 y 2012 hubo paridad relativa en el género de los sujetos pasivos de ataques con agentes químicos: de un total de 295 casos, 152 víctimas fueron mujeres (125 por violencia interpersonal y 27 por violencia intrafamiliar) y 143 hombres (117 por violencia interpersonal y 26 por violencia intrafamiliar). De hecho, en la ciudad de Bogotá, durante el mismo lapso de tiempo, la paridad es absoluta: de un total de 64 casos, 32 de las víctimas fueron mujeres (27 por violencia interpersonal y 5 por violencia intrafamiliar) y 32 fueron hombres (28 por violencia interpersonal y 4 por violencia intrafamiliar). Por lo tanto, no parece plausible afirmar que un género fue afectado de manera predominante por estos ataques, ni tampoco que estas figuras criminales sean delitos de género.

En tercer lugar, un sector del Congreso estimó que la modificación legislativa era de trascendental importancia debido a la imperiosa necesidad de aumentar el marco punitivo para los ataques con ácidos o sustancias corrosivas que causaren deformidad a las víctimas. Esta pretensión encontró sustento en una posición expansionista y populista, pues, para el grupo de congresistas que la impulsó resultaba completamente inaceptable que los atacantes que utilizaran estos medios para lesionar y deformar a sus víctimas pudiesen ser objeto de beneficios punitivos tales como la excarcelación o la libertad condicional. Concretamente abogaron por "Niveles de agravación punitiva a los responsables de estas conductas, para que estas en ningún caso admitan la excarcelación como está ocurriendo 
en la actualidad" (Proyecto de Ley 091 de 2011, segundo debate Cámara. Gaceta del Congreso, XXI(445), 24 de julio de 2012, p. 23).

En suma, hubo tres posiciones que influyeron de modo determinante en la aprobación de esta reforma legislativa. Tanto la primera como la tercera posición coinciden, prima facie, en estar sustentadas por un mayor desvalor de resultado. ${ }^{6}$ Esto se debe a que ambas comparten la idea de que la legislación anterior no sancionaba de forma idónea a los sujetos activos de esta conducta. Verbigracia, mientras que los congresistas que compartieron la primera posición consideraron que la relación de proporcionalidad entre el daño y la sanción era irrisoria, ${ }^{7}$ los de la tercera opinaron que esta modalidad delictiva no merecía tener ningún tipo de beneficio punitivo dada su gravedad. Dicha gravedad, a su vez, solo puede ser entendida como una deformidad superior al que otra clase de herramienta podría causar, puesto que, de lo contrario, las lesiones causadas con ácidos o sustancias corrosivas encajarían perfectamente en el tipo penal precedente y no hubiese habido necesidad, ni dogmática, ni político criminal de

6 "El desvalor de resultado del hecho reside en la lesión o puesta en peligro del objeto de protección de la acción, mientras que el desvalor de acción lo hace en la forma y modo de la comisión. El desvalor de acción consiste tanto en las modalidades externas del comportamiento del autor como en las circunstancias que concurren en su persona. De ahí que se distinga entre el desvalor de acción referido al hecho y al autor (personal). Con la asunción por el tipo penal del desvalor de la acción y del resultado uno y otro se convierten en injusto de la acción y del resultado" (Jescheck y Wiegend, 2002, p. 257).

7 "No obstante, se entiende que, por no encontrarse descrita con claridad la gravedad que acarrea este hecho punible, tenga como consecuencia que la pena impartida por el Administrador de Justicia no sea la adecuada, toda vez que no se logra equiparar tal delito y se deja de lado la parte física y en especial la psicológica de la víctima" (Proyecto de Ley 091 de 2011 Cámara, p. 20). crear uno nuevo. Por lo tanto, desde la óptica de los legisladores, la gravedad de la deformidad implicaba una afectación mayor al bien jurídico de la integridad personal y ameritaba ser tipificada de forma autónoma. Sin embargo, esta clase de ataques no conllevan, de forma necesaria, un mayor desvalor de resultado (ver más adelante el numeral II.C.3.d) en términos comparativos frente a las deformidades con secuela permanente causadas con medios diferentes a los previstos en la reforma legislativa. En consecuencia, resulta más adecuado calificar estas posiciones como populismo punitivo, cuya finalidad es generar prevención general negativa, ${ }^{8}$ que como un mayor desvalor de resultado.

Después de múltiples debates y conciliaciones entre la Cámara de Representantes y el Senado, el texto definitivo quedó aprobado de la siguiente forma:

Si el daño consistiere en deformidad física causada usando cualquier tipo de ácidos, álcalis, sustancias similares o corrosivas que generen daño o destrucción al entrar en contacto con el tejido humano, incurrirá en pena de prisión de setenta y dos (72) a ciento veintiséis (126) meses y multa de treinta y cuatro punto sesenta y seis (34.66) a cincuenta y cuatro (54) salarios mínimos legales mensuales vigentes.

Así, este se convirtió en uno de los tres tipos autónomos del reformado artículo 113 del cP.

8 "en efecto, la pena sirve como amenaza dirigida a los ciudadanos por la ley para evitar que delincan. Esto es, opera como 'coacción psicológica' en el momento abstracto de la tipificación legal” (Mir Puig, 2007, p. 53). 


\section{EL DELITO}

Ante todo, cabe advertir que el tipo penal no constituye, de forma exclusiva, una reforma al artículo 113 del cp sino una nueva aproximación a los delitos de lesiones personales en Colombia. Vale decir que el país tiene un sistema de lesiones personales que se ha caracterizado, de vieja data, por valorar el delito en virtud del resultado material y no por su forma de comisión u omisión (artículo 25 cP), razón por la cual este delito es un elemento novedoso para la forma de organización y clasificación de las lesiones personales. Sin embargo, para no prolongar lo que supone ser una breve introducción a este capítulo, este es tan solo uno de los tantos aspectos interesantes y relevantes que merecen la pena ser analizados sobre este tipo penal. Todo en aras de establecer cuál es su naturaleza y alcance dogmático.

\section{A. El bien jurídico}

El contenido material del bien jurídico ${ }^{9} \mathrm{es}, \sin$ lugar a dudas, una cuestión determinante al momento del análisis jurídico-penal del delito.

9 "el bien jurídico, debe entenderse como un valor abstracto del orden social protegido jurídicamente, en cuya defensa está interesada la comunidad y cuya titularidad puede corresponder a un individuo o a la colectividad" (Jescheck y Wiegend, 2002, p. 257); "Ciertamente el bien jurídico, como expresión del objeto de tutela legal, ofrece la clave de la interpretación y la base de la formación del sistema en la Parte Especial, pero no ha de limitarse a cumplir tal función metodológica, aunque a ella se haya reducido prácticamente su historia; el bien jurídico no lo decide el derecho positivo, sino que, por el contrario, está llamado a limitar al legislador: bien jurídico será solo aquello que merezca ser protegido por la ley penal. (...) El concepto de bien jurídico capaz de limitar al legislador no debe buscarse en la realidad naturalística ni en la valoración subjetivo-moral (no realizable mediante la coacción externa) sino en el terreno de lo social. Bienes jurídicos son condiciones necesarias, según la observación empírica, de un correcto funcionamiento de los sistemas sociales" (Mir Puig, 2007, p. 123).
Sin embargo, no parece haber unanimidad en la doctrina frente a si el contenido del bien jurídico es un límite material para el legislador 0 , si por el contrario, es el mismo legislador quien por medio de leyes nutre de contenido el bien jurídico. ${ }^{10}$ Lo cierto es que independientemente del contenido ontológico del bien jurídico, si es que tal cosa existe, el legislador colombiano sí tiene, por lo menos en principio, varios límites infranqueables a saber: la Constitución Política, los principios generales del derecho penal y el desarrollo jurisprudencial y doctrinal del contenido jurídico de estos, en particular el artículo 11 del cP.

En cuanto al contenido dogmático del bien jurídico aquí tratado es necesario decir que la doctrina colombiana, en general, parece aceptar que la denominación integridad personal no le hace justicia al contenido material del bien jurídico tutelado, dado que no abarca la totalidad de este y, por esta razón, sería errado limitarlo a la integridad física. En esta línea de pensamiento se encuentra Luis Carlos Pérez quien considera que "son más acertados los sistemas que describen este grupo de quebrantos como

10 "Aunque se parta -como he intentado exponer- de una teoría del bien jurídico crítica hacia la legislación ofrece conclusiones lo suficientemente claras, lo cierto es que sigue siendo una cuestión de máxima controversia la de cuáles son los efectos de una criminalización de modalidades de conducta que no supongan una afectación al bien jurídico. Los partidarios del bien jurídico no han sido capaces de poner suficientemente en clase si el postulado de la afectación a un bien jurídico supone una directriz político-criminal a ofrecer al legislador, pero que no lo vincula, o si, en cambio -y, en su caso, bajo qué presupuesto-, la falta de conexión con un bien jurídico puede conducir a la ineficacia de una disposición penal. Que la segunda alternativa no está completamente desencaminada desde un principio lo demuestra ya el hecho de que los tribunales constitucionales en Alemania, España y Argentina se han ocupado de tales preceptos, y que los tribunales extranjeros han llegado en los casos antes expuestos a una declaración de nulidad" (Roxin, 2013, pp. 20 y 21). 
lesiones corporales, pues toda disminución de la integridad del hombre, como ser biológico, tiene igualmente base objetiva" (1991, p. 226). Así, se ha entendido que la protección de este bien jurídico es dual, de tal suerte que protege tanto la integridad física como la salud de las personas (Gómez Méndez, 1998, p. 303; Pacheco Osorio, 1972, p. 391; Velásquez, 2013a, p. 237), elementos que estarían contenidos, si así se desea, en el concepto de integridad corporal (Gómez y Urbano, 2011, p. 1024) o personal, como lo denominan los artículos 111 cP y siguientes.

En el escenario internacional la discusión no es sustancialmente diferente. Mientras algunos autores consideran que el verdadero bien jurídico consiste en un concepto complejo de la salud, ${ }^{11}$ otros afirman que el ámbito de protección del bien jurídico debe ser la incolumidad personal. ${ }^{12}$ Así mismo, hay autores que comparten la visión de la doctrina colombiana y concluyen que el bien jurídico abarca una protección dual: salud e integridad física (Marín, 2008, p. 127; Donna, 2008, p. 259). La diferencia entre las distintas aproximaciones doctrinales al bien jurídico integridad personal parece ser, de forma exclusiva, el grado de protección. No obstante, ambos pro-

11 "Por eso decimos que la salud es un bien jurídico único de carácter complejo, en el cual queda englobada la integridad corporal, y que actualmente debe conceptualizarse conforme lo hace la oms (Organización Mundial de la Salud) como estado de bienestar físico, mental y social, y no meramente la ausencia de enfermedad o invalidez" (Bustos Ramírez, 2008, p. 89; (González Rus, 2011, p. 90; Molina Fernández, 2010, p. 664).

12 "que expresa la falta de lesión o daño, el estar indemne, lo que abarcaría tanto supuestos de ataques a la integridad —entendida como plenitud corporal (...) — como a la salud" (Álvarez García, 2011, p. 185; Buompadre, 2009, p. 221). tegen de forma homogénea al titular del bien jurídico, por lo cual termina siendo una diferencia más conceptual que práctica.

\section{B. El sistema de lesiones personales en Colombia}

Colombia tiene un sistema penal de lesiones personales mixto y residual. Las lesiones pueden ser simples (artículo 112 сP) o complejas (cP, artículos 113 y ss.; Tócora, 2009, p. 74; Arenas, 1986, p. 461). Las lesiones simples son aquellas que exigen, como condición objetiva de tipicidad, la existencia de una incapacidad para trabajar o enfermedad debidamente acreditada por el Instituto Nacional de Medicina Legal y Ciencias Forenses. Sin embargo, estas no se deben clasificar, únicamente, por el periodo de tiempo que el médico legista considere se esté incapacitado para desarrollar un trabajo ${ }^{13}$ sino, también, según el lapso de tiempo que se demorará el cuerpo morboso en volver al estado anterior a que las lesiones fueran causadas. Existen tres tipos de lesiones simples: (i) leves, si la incapacidad o enfermedad dura 30 días o menos; (ii) graves, si la incapacidad o enfermedad dura entre 31 y 90 días; y (iii) gravísimas, si la incapacidad o enfermedad excede de 91 días (artículos 111 y 112 del cP).

13 "Incapacidad laboral: Perturbación física o psíquica, que impide o imposibilita al sujeto pasivo realizar actividades productivas o laborales, durante un período que ha de oscilar dentro de los límites previstos en la disposición (...) La expresión se ha de entender en sentido amplio, es decir, se trata de la imposibilidad del sujeto pasivo de desarrollar su actividad vital, la cual le trae como necesaria consecuencia su improductividad. (...) Enfermedad: Alteración en el funcionamiento de uno o varios órganos o partes del cuerpo, ya sea que revista un carácter generalizado alteración total del funcionamiento del organismo o localizado -afectación de un miembro, órgano o función" (Pabón Parra, 2013, p. 67). 
A su turno, las lesiones complejas se caracterizan por la existencia de una secuela. Esta se define como las "alteraciones en la forma o en la función del órgano o miembro que persisten tras el vencimiento de la incapacidad médicolegal" (Gómez y Urbano, 2011, p. 1029). Estas lesiones personales podrán ser de carácter transitorio o permanente. Serán transitorias cuando la secuela desaparezca por el proceso de sanación del cuerpo morboso, y permanentes cuando estas no puedan ser corregidas o sanadas por el mero proceso de curación corporal (ver discusión ampliada en el numeral II.C.3.e).

El sistema es residual puesto que únicamente habrá lesión simple en el evento que no haya lesión compleja. ${ }^{14}$ En suma, ante la existencia de una secuela, bien sea esta de carácter transitorio o permanente, acompañada de una incapacidad para trabajar, materialmente solo se debe tener en cuenta la sanción penal de la lesión personal compleja. Lo anterior se debe al mandato legal expreso de la cláusula de absorción punitiva (art. $117 \mathrm{cP}$ ), la cual exige que, en los casos donde hay unidad teleológica de conducta o conducta única, solo se aplique la pena correspondiente a la del delito de mayor gravedad.

Una de las características fundamentales del sistema de lesiones personales en Colombia es que prácticamente todos los tipos penales, con excepción de la modificación legislativa que se estudia en este texto, se definen exclusiva-

14 La única excepción a esta regla será en el caso en que haya un concurso ideal entre una deformidad con secuela transitoria (art. $113 \mathrm{cP}$ ) y una incapacidad para trabajar o enfermedad superior a 91 días, situación en la cual, por lo menos en principio, la pena deberá ser tasada a partir de las lesiones gravísimas. mente por el resultado material, es decir, por la lesión y no por la forma comisiva del delito. Al respecto, afirmó acertadamente Arenas: “Ios medios, pues, carecen de relevancia para tipificar el delito de lesiones personales. Tan idóneos son los instrumentos cortantes, punzantes o contundentes, como las armas, las propias y las impropias, y las sustancias químicas (ácidos, venenos)" (1986, p. 459).

Por último, es necesario decir que la lesión personal como resultado material en general, contrario a la posición de Castro Cuenca (2011, p. 134), ${ }^{15}$ no exige tratamiento médico como requisito de tipicidad, elemento propio de la legislación española (art. 147 cp de España) ${ }^{16}$ y no de la legislación colombiana.

\section{Análisis del tipo penal}

\section{La deformidad}

Los diferentes tipos penales que sancionan las deformidades ${ }^{17}$ en el cuerpo humano protegen

15 "El resultado consiste en la causación de una lesión que requiera objetivamente, para su sanidad, tratamiento médico o quirúrgico, además una primera asistencia facultativa" (Castro Cuenca, 2011, p. 134).

16 "El que, por cualquier medio o procedimiento, causare a otro una lesión que menoscabe su integridad corporal o su salud física o mental, será castigado como reo del delito de lesiones con la pena de prisión de seis meses a tres años, siempre que la lesión requiera objetivamente para su sanidad, además de una primera asistencia facultativa, tratamiento médico o quirúrgico. La simple vigilancia o seguimiento facultativo del curso de la lesión no se considerará tratamiento médico".

17 En el ordenamiento jurídico colombiano hay tres tipos penales autónomos que sancionan las lesiones personales que generan deformidad, todos consagrados en el artículo 113 del Código Penal: i) las lesiones personales que generan deformidad transitoria, ii) las lesiones personales que generan deformidad permanente y iii) las lesiones personales causadas con ácidos, álcalis, sustancias corrosivas o similares que generen deformidades. Así mismo, existe un agravante específico 
una faceta especial del bien jurídico integridad personal: "el aspecto físico externo del individuo" (Romeo Casabona, 2004, p. 222). Ahora, frente al objeto de protección del tipo penal no parece haber mayor controversia, sin embargo, respecto a qué se considera deformidad sí la hay, lo que lleva a preguntarnos: ¿cuál es el grado de alteración física en un sujeto pasivo que determina la existencia de una deformidad?

Para el Diccionario de la Lengua Española la deformidad se define como lo desproporcionado o irregular en su forma. A nuestro juicio esta descripción no es conclusiva frente al alcance jurídico de la figura. Lo anterior se debe a que al guiarnos únicamente por dicha definición necesariamente tenemos que acudir a lo que es considerado proporcional o regular en aras de identificar lo que no lo es, convirtiéndose en un estudio completamente subjetivo y, por consiguiente, indeseable.

Vale la pena resaltar dos planteamientos en la doctrina nacional. Por un lado, el de los autores Gómez y Urbano quienes consideran que el presupuesto mínimo para que se configure la deformidad es "cualquier efecto importante que altera externamente de manera ostensible la forma, la simetría o la estética corporal en reposo o movimiento" (2011, p. 1028), mientras que para otros la deformidad se define como la alteración en la armonía de las partes que componen el cuerpo humano (Velásquez, 2013a, p. 250; Pérez, 1991, p. 239; Gómez Méndez,

ubicado en el mismo artículo 113 para estas tres clases de deformidades, el cual sanciona aquellas deformidades que afecten el rostro.
1998, p. 311; Ferreira Delgado, 2006, p. 96). En cuanto a la primera posición, es de rescatar que los autores contemplen la presencia de deformidades tanto en el cuerpo en reposo como en el cuerpo en movimiento, más aún ante la plausible existencia de una deformidad que solo sea perceptible cuando el cuerpo esté en movimiento. A pesar de lo anterior, consideramos que la ostensibilidad de la deformidad como criterio de tipicidad puede ser problemática. Sobre todo en aquellos eventos donde hay una alteración en la armonía estética del sujeto pasivo pero esta no es perceptible a simple vista. Es precisamente en esta instancia donde la primera y la segunda posición se distancian. La segunda no incluye dentro de su definición la ostensibilidad o magnitud de la alteración física sino que parte de la armonía de las partes que componen el cuerpo humano. ${ }^{18}$

Un ejemplo que permite ilustrar las desventajas de utilizar la ostensibilidad como criterio para determinar la existencia de la deformidad es el parámetro del sujeto pasivo con una armonía física previa. Una armonía física previa, para efec-

18 En España, el Tribunal Supremo utiliza como presupuesto mínimo para la existencia de la deformidad "toda irregularidad física visible y permanente que produzca que el sujeto sufra imperfección estética en la parte corporal afectada" (STS de 17 de febrero de 1996, citada por Cardona Torres, 2010, p. 94). Igual posición tiene Carlos Suárez-Mira al decir: "hablar de deformidad es hablar de irregularidades estáticas o dinámicas perceptibles a través de la vista y afectantes al aspecto o actuación externos del individuo. El aludido requisito de la visibilidad también se da aun cuando las partes o actuaciones corporales irregulares no queden por lo general expuestas a la vista o sean fácilmente ocultables" (2011, p. 104). Por otra parte, se pueden encontrar posiciones que le dan más importancia a la contextura del sujeto que a la perceptibilidad de la lesión, de tal manera que se considera la existencia de deformidad "aún en los supuestos en los que del cambio de forma no se puedan derivar 'efectos sociales o convivenciales negativos', siempre y cuando la modificación de la 'forma' sea relevante desde el punto de vista individual" (Álvarez García, 2011, p. 223; Gómez y Urbano, 2011, p. 1029). 
tos de este supuesto de hecho, debe ser entendida como la composición anatómica propia del sujeto antes de ser lesionado. Supongan que A, hombre con un prominente tabique desviado, es atacado por $\mathrm{B}$, quien le propina un fuerte golpe en la nariz y, contrario a su propósito de causar “daño", le corrige la desviación. La palabra daño está entre comillas debido a que dependiendo de la óptica con la que sea analizada habrá o no deformidad. Si consideramos que la deformidad es "la falta de proporcionalidad o de armonía entre las diferentes partes del cuerpo humano" (Arenas, 1986, p. 463) o que no hay "deformación del rostro si no trasciende estéticamente y desfigura la fisonomía lo que ocurrirá cuando el sentido antiestético del rostro lesionado "llame la atención' de los demás" (Donna, 2008, p. 300), necesariamente tendremos que concluir que no hay deformidad, ergo, por lo menos desde la óptica de este delito, sería una acción atípica. Por el contrario, si se acepta que la deformidad significa "que se ha alterado la identidad visual del sujeto, y ello aunque la nueva forma no sea socialmente repulsiva; incluso aunque fuera bella objetivamente" (Álvarez, 2011, p. 223), la respuesta es que B sería responsable del delito de lesiones dolosas que causaron deformidad como secuela.

En consecuencia, encontramos que la segunda posición es mucho más deseable que la primera $y$, por lo tanto, a nuestro juicio, la deformidad debe ser considerada como aquella alteración física causada en el cuerpo humano, indistintamente de los juicios de valor, positivos o negativos, a que pueda ser sometida. Esto se compagina con una concepción de la integridad personal fundada en la dignidad humana, a partir de la cual se concluye que lo jurídicamente relevante no es la opinión de un tercero frente a la alteración física del sujeto pasivo o su ostensibilidad, sino la alteración física desaprobada e injusta que sufra el sujeto pasivo. En este sentido se manifestó la Corte Constitucional (CCons.) cuando definió, a partir de la síntesis jurisprudencial realizada en la sentencia T-881/02, no solo el contenido jurídico sino los componentes esenciales, es decir, "la dignidad humana entendida como intangibilidad de los bienes no patrimoniales, integridad física e integridad moral". ${ }^{19}$

Por lo tanto, una postura como la de Mario Arboleda y José Armando Ruiz, quienes consideran que una persona "contrahecha" no puede ser sujeto pasivo del delito de deformidad dado que no es posible deformar a aquella persona que no tiene las características de un individuo promedio (2012, p. 655) ${ }^{20}$ es completamente inconstitucional. Al aceptar un argumento tan absurdo como este se estaría menoscabando la integridad física y la dignidad humana de aque-

19 Véase también CCons., sentencia T-572/99. M. P.: F. Morón: “Este término equivale al merecimiento de un trato especial que tiene toda persona por el hecho de ser tal y así se convierte en la facultad que tiene toda persona de exigir de los demás un trato acorde con su condición humana. De esta manera, la dignidad se erige como un derecho fundamental, de eficacia directa, cuyo reconocimiento general compromete el fundamento político del Estado colombiano".

"No creemos nosotros que se trate de la forma que, en concreto, presente el cuerpo del agredido, sino de la forma que, normal y ordinariamente, presenta el cuerpo en la especie humana, lo cual fundamentamos en el "principio de lesividad", recordando que lo que se está protegiendo aquí es la "integridad personal", y no la "integridad individual". No quiere ello decir, tampoco, que no pueda ocasionarse "lesiones corporales" a un contrahecho, argumentando que no se puede deformar lo que ya es deforme. No. Un contrahecho también podrá ser víctima de unas "lesiones corporales", si bien no por el concepto de 'deformidad', sí, por el de "incapacidad para trabajar" o por el de 'perturbación psíquica', en tanto resultados dañosos derivados de la conducta en contra suya desplegada por parte de un tercero". 
Ilos que hayan nacido con una discapacidad física, como por ejemplo labio leporino. Es totalmente inadmisible concebir que una persona que ha nacido con labio leporino no pueda ser sujeto pasivo de una deformidad causada con ácidos (asumiendo que la única parte afectada del cuerpo sea el labio superior) y solo pueda serlo de lesiones que generan incapacidad para trabajar o psíquicas, exclusivamente porque este, en palabras de los autores citados, es un sujeto "contrahecho".

Otra postura que tampoco debería ser empleada para decidir cuándo hay o no deformidad es aquella que considera que "no es lo mismo una lesión en el rostro para una reina de belleza - o aspirante a serlo- que para un boxeador" (Gómez Méndez, 1998, p. 312). Dicha distinción, que ya se planteaba a mediados del siglo anterior, ${ }^{21}$ contraría abiertamente tanto el principio de dignidad humana como el de igualdad (artículos 1 y 13 de la Constitución Política de Colombia). En otras palabras, para efectos de la protección penal del bien jurídico la lesión en el rostro que cause deformidad, con independencia de los agravantes propios del delito, es igual tanto para la reina de belleza, como para el boxeador, como para el presidente de la República. Más aún si se tiene en cuenta el principio aristotélico empleado por la Corte Constitucional para definir la igualdad, según el cual

21 "En efecto, una cicatriz en el rostro es indudablemente más grave en una mujer que en un hombre, porque si a los dos los afecta, las repercusiones sociales de la lesión tienen más trascendencia con respecto a aquélla que a este. La mujer, por disposición natural lleva en su rostro, en forma más perfecta que el hombre, los estigmas de la belleza. Su cara afeada por la lesión desmerece desde el punto de vista estético y muchas veces puede causarle más perjuicios que al hombre" (Gutiérrez Anzola, 1952, p. 196). "hay que tratar igual a lo igual y desigual a lo desigual" (sentencia C-022/96). Al no haber un argumento razonable para tal discriminación debemos concluir que al tenor del artículo 13 de la Constitución Política sería inconstitucional hacerla.

Lo anterior no implica, de forma alguna, que dicha discriminación no sea válida en la esfera del derecho civil. Es válida en el entendido que la tasación pecuniaria de la indemnización de perjuicios se realiza a partir del daño económico causado o por causarse (lucro cesante, daño emergente o perjuicio moral presente y futuro), cuyo monto no es homogéneo en la gran mayoría de los casos y debe ser apreciado de modo casuístico.

En suma, consideramos que es posible concluir que la deformidad, como faceta de protección del bien jurídico integridad personal, debe ser comprendida desde la dignidad humana y, en general, desde el derecho constitucional. Así se evitan criterios de valoración tan indeseables como la repugnancia, la visibilidad u ostensibilidad de la lesión para calificarlas como tal, y se parte de la forma anatómica del sujeto pasivo, con independencia de los juicios de valor que se puedan hacer de su contextura física o de las características inherentes a su ser, para hacer una valoración real del cambio estético causado por la lesión.

\section{El tipo penal}

Volvamos sobre el artículo 13 de la Ley 1639 de 2013: 
Si el daño consistiere en deformidad física causada usando cualquier tipo de ácidos; álcalis; sustancias similares o corrosivas que generen daño o destrucción al entrar en contacto con el tejido humano, incurrirá en pena de prisión de setenta y dos (72) a ciento veintiséis (126) meses y multa de treinta y cuatro punto sesenta y seis (34.66) a cincuenta y cuatro (54) salarios mínimos legales mensuales vigentes.

Antes de realizar el análisis correspondiente al tipo penal autónomo es necesario hacer una breve reseña sobre los aspectos más importantes de la modificación legislativa. Una vez hecho esto se procederá a estudiar los elementos objetivos y subjetivos del tipo penal.

La principal diferencia que introduce este tipo penal se da en el ámbito del sistema de lesiones personales. El sistema de lesiones personales, como se señaló en el aparte B de este capítulo, se caracteriza por valorar de manera prevalente el resultado material, sin embargo, la modificación legislativa introdujo un nuevo componente: la valoración del medio comisivo como elemento del injusto penal.

\section{Aspecto objetivo del tipo penal}

\section{a) Sujetos}

En cuanto a los sujetos, es necesario decir que tanto el sujeto pasivo como el sujeto activo son comunes. Por consiguiente, cualquier persona, en principio, puede ser sujeto activo o pasivo de este tipo de lesiones. Lo dicho, como es natural, incluye tanto a menores como a inimputables (artículo $33 \mathrm{cP}$ ).
Frente al sujeto pasivo no existe ninguna restricción. Cualquier ser humano podrá ser sujeto pasivo de esta modalidad delictiva, lo cual es de aplaudir si tenemos en cuenta la orientación de género que tuvo en un principio el proyecto de ley. Más aún si se considera, como se hizo en el numeral I.B, que las cifras de sujetos pasivos no reflejan una particular o predominante afectación al género femenino. Si hubiera sido de otra forma, se estaría generando una discriminación estadísticamente infundada en contra de aquellos sujetos pasivos atacados con ácidos que no sean mujeres. Por consiguiente, al haber paridad en las cifras de ataques frente al género de los sujetos pasivos, mal hubiera hecho el legislador al calificar el sujeto pasivo de este tipo autónomo. Esto no implica, de forma alguna, que aquellos ataques con ácidos donde haya un desvalor adicional en razón de la discriminación de género, raza u orientación sexual, entre otros, pueda quedar impune. Para valorar dicho injusto se encuentran los agravantes tanto específicos (artículos 119 y 104 numeral 11 del cP) como genéricos (artículo 58 numeral 3 del $\mathrm{CP})$.

\section{b) Objeto jurídico y objeto sobre el cual recae la acción}

Como se indicó en el aparte II.A, el objeto jurídico protegido por el bien jurídico integridad personal en este aspecto concreto es el fenotipo de cada ser humano y su integridad física y psíquica. En este orden de ideas, el objeto sobre el cual recae la acción tiene que ser el cuerpo humano. 


\section{c) Verbo rector único de conducta específica}

El verbo rector es causar y el resultado es la deformidad, por lo tanto nos encontramos ante un tipo penal de resultado en sentido material, dicho lo cual, para su consumación será necesaria la causación efectiva de la deformidad. En concordancia con lo expuesto en el aparte anterior, la deformidad se presentaría en aquellos eventos donde la acción desplegada por el sujeto activo tiene una incidencia que altera la armonía en las formas del sujeto pasivo. Desde luego, dicha incidencia tiene que superar el umbral de las lesiones tipificadas en el artículo 112 del cP, de lo contrario serán unas lesiones simples. En otras palabras, uno de los requisitos sine qua non para que se pueda catalogar una lesión personal como compleja es la existencia de una secuela, pues de no haberla el resultado no es propio de las lesiones personales complejas y deberá ser clasificado dentro de las lesiones simples.

Ahora, en cuanto al modo de comisión de la conducta, el tipo penal exige que el daño, en este caso la deformidad, se materialice por medio de la utilización de ácidos, álcalis, sustancias corrosivas o sustancias similares. Por lo tanto, al tratarse de un tipo penal autónomo 'cerrado', si la deformidad es causada por un medio diferente a los estipulados expresamente en él, la acción será atípica frente a este delito. d) Los medios

Los medios de ejecución de la conducta son cruciales no solo para tipificar el delito de lesiones personales, sino para identificar por qué es un delito de consumación instantánea. Dentro de los medios plasmados por el legislador en este nuevo tipo penal se encuentran: (i) los ácidos, (ii) los álcalis, (iii) las sustancias similares y (iv) las sustancias corrosivas.

Para ilustrar sobre los ácidos nos basaremos en Brown, LeMay, Bursten y Burdge (2004). Los ácidos "son sustancias que ionizan en disoluciones acuosas para formar iones hidrógeno y así aumentar la concentración de iones $\mathrm{H+}$ " (p. 121). En cuanto a estos, el legislador adoptó el término sin hacer distinción alguna pero, lo cierto, es que más allá de ser una categoría absoluta los ácidos, según los autores citados, son clasificados en tres categorías: fuertes, débiles y despreciables (p. 619). Estas categorías, a su vez, se clasifican según su pH, el cual debe ser, sin excepción alguna, inferior a 7. Entre más cercano el pH sea a 0 más ácida será la sustancia y, por el contrario, entre más cercana sea a 7 será menos ácida y más neutra. El legislador, sin embargo, ató el medio empleado al resultado, es decir, solo será idónea la acción en la cual se emplee un ácido que genere daño. En consecuencia, la saliva (una sustancia ácida pero catalogada como un ácido despreciable) o el zumo de limón no podrán ser considerados uno de los ácidos a los que se refiere este precepto legal, dada su inidoneidad para causar daño con el mero contacto con la piel humana (p. 623). 
Los siete ácidos más fuertes y comunes son: el ácido clorhídrico ( $\mathrm{HCL}$ ), el ácido bromhídrico ( $\mathrm{HBr}$ ), el yoduro de hidrógeno (HI), el ácido nítrico (HNO3), el ácido clórico (hCLO3) y el ácido perclórico (hcLo4) (p. 625). Al igual que el ácido sulfúrico, aunque técnicamente este es catalogado como un ácido poliprótico (p. 635), todas estas sustancias son altamente corrosivas y generan daño, en magnitudes considerables, tan pronto entran en contacto con el cuerpo humano.

A diferencia de los ácidos, que el legislador optó por tipificarlos como un género, los álcalis son una especie de las bases, el fenómeno opuesto de los primeros. Por definición, las bases cuentan con un $\mathrm{pH}$ superior a 7 e inferior a 14; de forma similar a los ácidos, entre más cercanas a pH 14 más fuerte son y entre más cercanas a pH 7 menos fuertes y más neutras serán.

El Diccionario de la Lengua Española define el álcali como “hidróxido metálico muy soluble en el agua, que se comporta como una base fuerte". En cuanto a las bases fuertes es necesario decir que no existen muchas y “las solubles más comunes son los hidróxidos iónicos de los metales alcalinos (grupo 1A) y de los metales alcalinotérreos (grupo 2A)" (Brown, LeMay, Bursten y Burdge, 2004, p. 627). Dentro del grupo 2A se encuentran, por ejemplo, el $\mathrm{NAOH}$ (hidróxido de sodio, comúnmente conocido como soda cáustica), el кон (hidróxido de potasio, utilizado para fabricar jabones y blanqueadores) y el $\mathrm{CA}(\mathrm{OH}) 2$ (hidróxido de calcio, usado para el tratamiento de cueros y en productos para el cabello). Todos estos compuestos químicos tienen en común el alto riesgo para la salud, puesto que pueden generar desde una quemadura al entrar en contacto con la piel hasta daños pulmonares al ser inhalados.

En cuanto a las "sustancias similares" es necesario anotar, tal como lo hace el profesor Fernando Velásquez (2013a), que al incluirlas en el texto legal "se introduce un notable margen de indeterminación al supuesto de hecho" ( $p$. 256), cuestión que compromete la eficacia del principio de taxatividad penal. En consecuencia, para determinar si la sustancia similar encaja o no dentro del presupuesto legal de este tipo penal es necesario responder si la similitud debe versar sobre las características esenciales de los ácidos o álcalis o sobre el resultado material. La respuesta es que debe ser sobre ambos. Por una parte, debe haber similitud en cuanto a las características de estos elementos, por lo tanto deben ser, necesariamente, solubles en agua y corrosivos. De lo contrario estaríamos ante otra clase de sustancias que no cumplen con el requisito de similitud y, por ello, su uso sería atípico frente a este delito, pero típico de las deformidades previas (con secuelas transitorias o permanentes).

Al utilizar el término sustancias corrosivas el legislador nos indica, por oposición, que los ácidos y las bases no son las únicas sustancias que producen corrosión, lo cual no es cierto. La corrosión es un efecto propio de los ácidos y las bases, específicamente de los expuestos anteriormente. Ahora bien, hay sustancias o medios que pueden producir efectos visualmente similares a la corrosión dado que esta, por definición, es un tipo específico de quemadura. En 
consecuencia, las quemaduras producidas con nitrógeno líquido, gasolina, electricidad o similares son atípicas en lo concerniente a este delito, lo cual constituye, sin lugar a dudas, un despropósito enorme.

Teniendo en cuenta que los medios contenidos en este delito implican un resultado material inmediato al entrar en contacto con la piel -la corrosión de esta- y que dicho resultado, a su turno, conlleva en mayor o menor medida una alteración de las formas y armonía corporal de cualquier sujeto pasivo, tiene perfecto sentido que sea un delito de consumación instantánea y efectos permanentes.

Por estas razones, es viable afirmar que uno de los fundamentos que justifica este tipo autónomo es un mayor desvalor de acción objetivo. Esto en virtud de que el medio elegido por el sujeto activo asegura ex ante el resultado material deseado que, para el caso en concreto, es la deformidad. Así mismo, se puede sostener que no hay un mayor desvalor de resultado dado que no es posible afirmar la existencia de una afectación más intensa al bien jurídico protegido por la simple utilización de los medios aquí en discusión. De hecho, es plausible obtener la misma afectación empleando medios distintos a los plasmados en este tipo. La utilización de electricidad o gasolina para quemar al sujeto pasivo, por ejemplo, podría obtener el mismo resultado y es un medio ajeno a los contemplados en el nuevo delito. Otro factor que nos lleva a concluir esto, es que el legislador impuso el mismo tope punitivo para ambos tipos de deformidades, aceptando implícitamente que es posible llegar al mismo resultado utilizando diferentes mecanismos.

e) El resultado en el tiempo ¿le aplican las secuelas transitorias o permanentes al nuevo tipo penal?

En cuanto a la transitoriedad o permanencia de las secuelas el legislador guardó silencio. Es decir, a diferencia de los delitos de lesiones con deformidad vigentes con anterioridad a la modificación legislativa, que tasaban una pena para la secuela transitoria y otra para la secuela permanente, el nuevo tipo penal trata de igual forma ambos eventos al guardar silencio.

Dicho silencio tiene varias repercusiones importantes en el ámbito de la imputación del delito. La primera, que el nuevo tipo penal autónomo es completamente ajeno a la discusión sobre si la lesión reparable es transitoria (Velásquez, 2013a, p. 251; Ferreira, 2006, p. 93) ${ }^{22}$ o permanente (Pérez, 1991, p. 241)23; la segunda, que está directamente relacionada con la primera, es que no resulta viable obtener los beneficios dados por la Corte Suprema de Justicia, Sala de Casación Penal (proceso n. ${ }^{\circ} 33289,5$ octubre

22 Autores a favor de que la lesión reparable sea de naturaleza permanente: "se dice que la mutación debe ser transitoria, porque cede o es modificable en el tiempo, como sucede con unas lesiones de las cuales quedan algunas cicatrices que desaparecen luego"; "La desfiguración es permanente cuando la estética corporal o facial se ha alterado de manera que por desarrollo natural no desaparezca con el tiempo".

23 Autor a favor de que la lesión reparable sea de naturaleza transitoria: "Deformidad permanente es la que no permite restaurar las formas del ofendido, durante el tiempo que a este le quede por vivir. La permanencia, tiene, pues, sentido total, es decir, que si existe la posibilidad de restauración bien por medio de la cirugía estética o por cualquier otro procedimiento la deformidad es transitoria". 
de 2011, M. P.: María del Rosario González) ${ }^{24}$ para los casos en donde las lesiones permanentes han sido reparadas. Beneficios punitivos bastante atractivos para el sujeto activo dado que implican cambiar la naturaleza de la secuela imputada de permanente a transitoria. Ahora, con independencia de los reproches y reparos que se le puedan hacer a la controversial posición de la Corte Suprema de Justicia, Ios plausibles beneficios ya no podrán ser objeto de discusión en un proceso penal. Menos aún después de la reforma al Código Penitenciario (art. 32, Ley 1709-2014) ${ }^{25}$ la cual proscribe cualquier clase de beneficio para los sujetos activos de este delito exceptuando las atenuaciones propias del sistema punitivo.

En resumidas cuentas, desde la perspectiva de este delito resulta innecesario establecer si la secuela es transitoria o permanente. Estos conceptos son netamente extraños al nuevo tipo penal autónomo, pues, como ya se dijo, no res-

$24 \mathrm{Si}$, por ejemplo, el delito es cometido dolosamente y la lesión fuese reparable, el sujeto activo no tiene un verdadero incentivo, aparte de una atenuación genérica por reparación a la víctima, aun cuando sea parcial y monetaria (artículo 55 numeral 6 del CP). Por el contrario, previo a la modificación legislativa, si el sujeto pasivo se encontraba en la misma situación podía sufragar el costo de la reparación y volver la lesión con secuela permanente en una lesión con secuela transitoria, que es, a su vez, querellable y desistible. La Corte realizó esto al aplicar el artículo 42 de la Ley 600, amparada en el principio de favorabilidad, para modificar la naturaleza de la secuela siempre y cuando la reparación de la lesión personal no sea una mera posibilidad sino, exclusivamente, en los casos en que se haya reparado efectivamente.

"Modifícase el artículo 68A de la Ley 599 de 2000 el cual quedará así: Artículo 68A. Exclusión de los beneficios y subrogados penales. No se concederán; la suspensión condicional de la ejecución de la pena; la prisión domiciliaria como sustitutiva de la prisión; ni habrá lugar a ningún otro beneficio, judicial o administrativo, salvo los beneficios por colaboración regulados por la ley, siempre que esta sea efectiva, cuando la persona haya sido condenada por delito doloso dentro de los cinco (5) años anteriores. Tampoco quienes hayan sido condenados por delitos dolosos (...) lesiones personales con deformidad causadas con elemento corrosivo (...)". ponde a la lógica del mayor o menor desvalor de resultado que ellas comportan, sino a un mayor desvalor de acción.

\section{f) La tentativa}

Por último, se encuentra la tentativa ${ }^{26}$ (art. 27 СP) como dispositivo amplificador del tipo penal. La tentativa en las lesiones personales ha sido, históricamente, un tema complicado de tratar. Algunos autores niegan su posible configuración. Por ejemplo, Francisco José Ferreira la descarta tajantemente afirmando que "la tentativa de lesiones personales nos parece imposible" (2006, p. 78). Por otra parte, se encuentran autores como el profesor Velásquez, quien considera que "nada se opone desde el punto de vista teórico a afirmar que es viable la presencia de este dispositivo amplificador del tipo" (2013a, p. 246), ${ }^{27}$ pero en la práctica resulta difícil, por no decir imposible, determinar cuál era el resultado pretendido. Pérez, de forma similar a Velásquez, acepta la existencia de una posibilidad teórica de la tentativa en las lesiones pero descarta de tajo su aplicación práctica puesto que la considera imposible (1991, p. 230). Es más, hasta autores como Gutiérrez Anzola, con

26 "La tentativa presupone tres aspectos: la resolución a la realización del tipo como elemento subjetivo, la inmediata puesta en marcha de la realización del tipo como elemento objetivo y la ausencia de la consumación del tipo como factor negativo conceptualmente necesario" (Jescheck y Wiegend, 2002, p. 553); "Por tanto, lo más acertado es partir de una teoría objetivo-subjetiva, para la cual el castigo de la figura en examen se justifica no solo porque el agente realiza conductas socialmente relevantes que buscan el menoscabo de los bienes jurídicos protegidos, sino porque hacia ellos está dirigido el plan concreto del autor; la tentativa, pues, se pune no solo por ser una mera manifestación de voluntad, sino por la lesión y menoscabo corrido por lo bienes jurídicos, producto del comienzo de la ejecución de un comportamiento dañoso" (Velásquez, 2013b, p. 615).

Véase también: Gómez Méndez, 1998, p. 315; Arboleda y Ruiz, 2012, p. 652. 
una óptica propia de la escuela positivista italiana, anticiparon los problemas que la tentativa generaba en este delito (1952, p. 180). ${ }^{28}$

En consecuencia, hay cuatro posiciones diferentes: i) quienes consideran que no es posible ni en la teoría ni en la práctica, ii) quienes creen que es teóricamente válido pero prácticamente difícil, iii) quienes opinan que es teóricamente válido pero prácticamente imposible y iv) por último, los que piensan que teóricamente es válido, de difícil aplicación práctica y en aquellos casos donde la indeterminación fáctica impida determinar a ciencia cierta cuál era la finalidad del autor (qué tipo de lesión pretendía causar el sujeto activo) se deberá imponer la pena mínima (Gómez y Urbano, 2011, p. 1034).

Pero esos impases no se presentan en este caso por dos razones: (i) no hay una indeterminación entre la acción desplegada y el resultado deseado, por lo tanto, no hay incertidumbre frente a cuál de los tipos penales que sancionan las lesiones personales se debe aplicar. Esta certeza se refuerza, aún más, teniendo presente que no puede haber una disyuntiva entre la existencia de secuelas transitorias o permanentes; (ii) al convertir los medios empleados en un elemento objetivo del tipo y que su idoneidad hace las veces de indicio denotador sobre el elemen-

28

"Solamente en el terreno de lo abstracto podría suponerse la existencia de una tentativa de lesiones, si se acomoda a ese fenómeno los elementos generales que constituyen la tentativa. Pero, a la vez, se presentan grandes dificultades que reducen el problema a la negativa. (...) podría admitirse en el campo de la teoría que el atacante es un sujeto peligroso y que su intento es digno de una represión penal; pero en la práctica habría de calcular qué lesión se iba a causar, qué incapacidad habría de producir ella y qué consecuencias habrían de derivarse, lo cual sería imposible". to volitivo de la acción, el dispositivo amplificador del tipo es completamente plausible. Por lo tanto, es correcto afirmar que una persona que arroja ácido a otra pero falla, bien por poca destreza o por la reacción oportuna del atacado, comete una tentativa de lesiones dolosas complejas, cuya secuela es la deformidad causada con ácidos.

Desde luego, no está de más afirmar, como se encuentra implícito en los ejemplos dados en el párrafo anterior, que para poder hablar de tentativa en este delito es necesario que se supere el umbral del mero acto preparatorio y se esté en sede de la ejecución idónea e inequívoca de la acción. Por consiguiente, no sería correcto imputar una tentativa de lesiones que causen deformidad, por ejemplo, a quien porta una botella que contenga ácido y, paralelamente, haya manifestado su intención de lesionar a alguien, en sentido genérico.

\section{Aspecto subjetivo del tipo penal}

Este delito, al igual que todos los tipos penales de lesiones personales, puede presentarse tanto en modalidad dolosa como en modalidad culposa. A su vez, podrá realizarse con dolo directo de primer grado, dolo directo de segundo grado o de consecuencias necesarias, dolo eventual (art. $22 \mathrm{cP}$ ) y presentarse con culpa consciente o culpa inconsciente (art. $23 \mathrm{cP}$ ).

Adicionalmente, la mayoría de la doctrina reconoce que "No basta con el dolo genérico de lesionar, sino que, como en cualquier otro delito, es preciso que la intención del sujeto compren- 
da el resultado producido, siquiera sea de forma eventual" (González Rus, Morillas Cueva, Peris Riera, Del Rosal Blasco y Sainz-Cantero, 2011, p. 94). ${ }^{29}$ En consecuencia, todo resultado material lesivo para la integridad personal que no quede cubierto por la esfera del dolo, entendido hasta dolo eventual, y que exceda el ánimo inicial del autor tendrá que entrar al ámbito de los delitos culposos, de los errores o de las acciones justificadas. Frente a esta cuestión consideramos que tales situaciones deberán resolverse en sede de concurso, contrario a Gómez y Urbano (2011, p. 1015), dado que no es viable aplicar la figura jurídica de la preterintención en los delitos de lesiones personales por la expresa prohibición legal que hace la legislación penal colombiana (art. $21 \mathrm{cP}$ ). ${ }^{30}$

\section{a) Dolo}

En este orden de ideas, la acción se presentará con dolo directo de primer grado cuando "precediendo el conocimiento de los hechos constitutivos de la infracción penal, también existe voluntad de realización del agente respecto de la producción del resultado típico concreto" (Posada Maya, 2008, p. 57). Así, por ejemplo, cuando un sujeto arroje voluntariamente alguna de las sustancias consagradas en el nuevo tipo penal, con la finalidad de deformar al sujeto pasivo, estaremos ante este tipo de dolo.

29 Véase también: "Desde el punto de vista subjetivo, no es aceptable un dolo genérico e indeterminado de lesiones, el dolo ha de ser en todo caso al menos eventual respecto al resultado" (Romeo Casabona, 2004, p. 208).

30 Código Penal. Artículo 21: "la conducta es dolosa, culposa o preterintencional. La culpa y la preterintención solo son punibles en los casos expresamente señalados por la ley" (itálicas fuera del texto original).
Habrá dolo directo de segundo grado o de consecuencias necesarias cuando el sujeto activo desee deformar al sujeto pasivo pero para hacerlo sea estrictamente necesario afectar la integridad de otra persona. ${ }^{31}$ Así, por ejemplo, se presentará en el evento donde, para lesionar a "B" sea necesario lesionar concomitantemente a "C".

Por el contrario, se configurará el dolo eventual (inciso $2^{\circ}$ art. $22 \mathrm{cP}$ ) cuando el sujeto activo lance la sustancia corrosiva por la ventana de un edificio aledaño a una acera usualmente transitada por personas dejando completamente al azar la lesión de un individuo (Velásquez, 2013b, p. 392), es decir, cuando prevea como posible la afectación a un tercero y, sin importar esto, deje voluntariamente al azar la posible producción del resultado material.

También se podrá presentar en la modalidad de comisión por omisión (art. 25 cp), esto es, en el evento en que, por ejemplo, un padre de familia cuya profesión es la ingeniería química, deje en la cocina un frasco plástico que contiene soda cáustica y su hijo, pensando que es agua común y corriente, la utilice para limpiar una mancha de comida en la camiseta que lleva puesta, causándose quemaduras severas. Desde luego, este caso no podrá ser agravado por el numeral primero del artículo 104 puesto que la posición de garante surge de la estrecha comunidad de

31 "Se presenta cuando el sujeto, respecto a la producción de una infracción típica, por un lado la prevé como consecuencia —extremadamente probable - inevitable derivada de la utilización de los medios elegidos para la puesta en marcha de la acción voluntaria principal; y por otro, la asume o co-quiere - aunque no la desee o le resulte desagradable-como condición necesaria para conseguir el fin propuesto" (Posada Maya, 2008, p. 58; Velásquez, 2013b, p. 392). 
vida, de otra forma se estaría violentado el principio del non bis in idem.

\section{b) Culpa}

Por otra parte, de acuerdo con Velásquez (2013b), habrá culpa con representación cuando, por ejemplo, un asistente de laboratorio que está realizando la disolución de un ácido, convencido por su experticia de que el líquido es inofensivo le pide a otro de los asistentes que introduzca la mano en el frasco; no obstante, el primero estaba equivocado puesto que el líquido no era inofensivo y causa graves quemaduras al segundo (p. 447). Habrá culpa sin representación cuando, por ejemplo, un conductor temerario omite dolosamente una señal de tránsito y choca con un camión que está transportando sustancias corrosivas, el tanque del camión se fisura y salpica a un transeúnte causándole quemaduras en la piel (p. 448).

\section{c) Otras hipótesis}

Frente a la posibilidad de imputar homicidio simple en grado de tentativa en los casos de ataques con ácidos, tal y como lo hizo la Fiscalía General de la Nación (7 de abril de 2014), es necesario tener en cuenta, a nuestro juicio, dos factores: (i) La modalidad o el medio empleado para realizar la acción. No es lo mismo si se le arroja a una persona una botella de ácido en la cara o en el cuerpo a si esa persona es arrojada a un estanque lleno de ácido. En estos casos es plausible inferir a partir de la modalidad, a título de indicio detonador, el ánimo del sujeto activo y la idoneidad objetiva del medio empleado para causar un daño. (ii) El ánimo del sujeto ac- tivo. Dicho elemento resulta trascendental para identificar la finalidad del autor y poder tipificar adecuadamente la responsabilidad penal, sobre todo, en aquellos casos donde la modalidad no es concluyente. Por ejemplo, si el autor de la conducta utiliza un gotero para verter ácido únicamente en los ojos del sujeto pasivo, es viable concluir que este desea privar al sujeto pasivo de la vista. Así mismo, si el autor arroja el mismo líquido de forma indiscriminada en el rostro del sujeto pasivo podríamos decir que su intención es deformar. Sin embargo, si este mismo sujeto arroja el ácido en el rostro de otro y, adicionalmente, le es encontrado en su teléfono móvil un mensaje de texto por medio del cual manifiesta, de forma clara, el ánimo homicida, aun cuando sea en sede de dolo eventual el panorama tiene que ser diferente. En un evento como este consideramos que sería correcto hacer tal imputación (tentativa de homicidio simple) a título de dolo eventual. Esto en virtud de que el sujeto activo acepta, ex ante, la posibilidad de que el sujeto pasivo muera y lo deja librado al azar. En un supuesto como este existirían dos ánimos diferentes, a saber: el de lesionar, como dolo directo de primer grado, y el de matar, como dolo eventual. Es más, si se acepta la existencia de dos bienes jurídicos diferentes, vida e integridad personal, podrían hasta concursarse idealmente.

Desde luego, esta cuestión deberá ser objeto de un análisis independiente para cada caso en concreto, puesto que no es viable establecer una regla general para todos los casos de ataques con ácidos. Ahora bien, lo que sí es cierto es que las lesiones personales complejas con secuela de deformidad deben ser el punto de 
partida del ente acusador. Más aún si se acepta, como se hizo en el capítulo anterior, la existencia de un elemento volitivo específico para esta clase de lesión.

En conclusión, consideramos que la tentativa de homicidio simple en los ataques con ácidos es perfectamente posible. Sin embargo, esto no quiere decir, de forma alguna, que de un ataque con ácido promedio pueda derivarse a priori tal imputación jurídica. El dolo homicida, aunque sea eventual, tiene que contar con conocimiento actual, elemento que debe ser probado y no presumido. Por lo tanto, al no ser posible derivar del mero ataque con ácido la existencia de tal conocimiento, sino por el contrario, confirmar la existencia del dolo de lesiones personales como un delito, y del dolo de deformar como especie, sería errado imputar tentativa de homicidio simple y no unas lesiones personales complejas con secuela de deformidad causadas con ácidos consumadas. Ahora bien, si se presenta una situación de esta naturaleza, donde el sujeto activo no previó el resultado de muerte y el sujeto pasivo muere, lo más adecuado sería imputar un homicidio preterintencional y no un homicidio simple o agravado.

\section{D) Análisis de punibilidad}

En esta área se encuentra uno de los cambios más interesantes de la reforma legislativa: la modificación del quantum punitivo frente a esta modalidad delictiva. Pero lo que Ilama la atención de forma particular es que solo haya sido modificado el marco mínimo o inferior y no el máximo o superior. Esto nos lleva a conside- rar, como se hizo en el análisis de los medios (II.C.3.d), que el legislador, de forma implícita, cree que puede haber un desvalor de resultado de igual magnitud, en términos de deformidad, causado con un medio diferente a los consagrados en el nuevo precepto legal.

Ahora bien, el propósito de este aparte es medir las ventajas y desventajas que acarrea el nuevo delito, estudiándolo desde la óptica del principio de plena valoración del injusto penal y el non bis in ídem.

\section{La cláusula de absorción}

La cláusula de absorción se encuentra plasmada en el artículo 117 del cp y nos indica que si se produjeren, como consecuencia de una conducta, varios resultados (refiriéndose a las lesiones personales) solo se aplicará la pena correspondiente al de mayor gravedad. Para el profesor Posada Maya la absorción punitiva es el modelo según el cual:

basta con la aplicación sic et simpliciter de la pena correspondiente a la conducta punible más grave entre las concurrentes, para satisfacer el grado de injusto del delito y la culpabilidad del autor - poena mayor absorbet poena minorem-, ello con independencia del número de infracciones a la ley penal realizadas por el agente (2012, p. 180).

Sin lugar a dudas, las implicaciones que tiene una cláusula de absorción no son minúsculas. En términos jurídicos una cláusula de esta naturaleza nos indica que el injusto de mayor penalidad comprende, adecuadamente, todas las 
acciones desplegadas por el sujeto activo. En lo referente a esta cláusula de absorción (art. 117 $\mathrm{CP}$ ), por su redacción ("si como consecuencia de la conducta") solo parece aceptar aquellos eventos en donde hay única acción o unidad de acción en sentido teleológico. Por lo tanto, aplicaría para aquellos casos en que haya concurso ideal pero no podría ser aplicable cuando se presente un concurso real de conductas (art. $31 \mathrm{cP}$ ).

Lo cierto es que, para las lesiones causadas con sustancias corrosivas, la existencia de esta cláusula de absorción es nefasta. Para explicar por qué, describiremos la naturaleza, primero del artículo 116 del cp, después la del nuevo tipo penal y, finalmente, expondremos los motivos.

El artículo 116 del cP consagra la pérdida anatómica o funcional de un órgano y, al final, el agravante para los casos donde se presenta la pérdida anatómica del órgano o del miembro. Este delito presupone, por lo menos en principio y para la modalidad dolosa, la intensión por parte del autor de privar intencionalmente al sujeto pasivo de una función determinada del cuerpo humano, por ejemplo, la vista. Así, a gracia de ejemplo, esta lesión se presenta cuando el sujeto activo le extrae ambos ojos al sujeto pasivo con la finalidad de privarlo de la función visual. Esta acción no solo sería penada por el primer aparte del artículo 116 cP, sino que estaría agravada por la pérdida anatómica del órgano. Ahora bien, la acción desplegada en este ejemplo no implica exclusivamente la pérdida anatómica. Como bien lo señala Pérez - quien tiene un concepto de la deformidad bastante extenso pero no por eso menos acertado- en las acciones donde hay una perturbación o pérdida funcional existe una deformidad correlativa (1991, p. 240). ${ }^{32}$ Así, la extracción de los ojos implica una deformidad en el cuerpo, deformidad copenada gracias a la cláusula de absorción, que implica un mayor desvalor de resultado y explica una sanción punitiva mayor (el agravante). La deformidad en este supuesto se presenta, al menos, con dolo de consecuencias necesarias.

Por otra parte, tenemos el nuevo precepto legal. Para ilustrar este caso invertiremos el ejemplo. El dolo directo será deformar el rostro por medio de la utilización de sustancias corrosivas. Sin embargo, como lo indica Hooma Shah “el ácido disuelve la carne y los huesos y puede destruir por completo características faciales como los ojos o la nariz" (2009, p. 1173), por consiguiente, cuando se arroja la sustancia corrosiva en el rostro hay una alta posibilidad de que se presente o una perturbación funcional o una pérdida anatómica. Asumamos que a raíz de un ataque con una sustancia corrosiva, donde el dolo directo del autor es deformar, se pierden ambos ojos, pérdida que se da, al menos, a título de dolo eventual. Para este caso la tipificación punitiva, por mandato legal del artículo 117 cP, tiene que ser idéntica a la del primer ejemplo, es decir, una pérdida anatómica agravada.

En resumidas cuentas tenemos dos casos: en el primero solo se presenta la extracción de los ojos, que implícitamente acarrea una deformi-

\footnotetext{
32 "es incuestionable que el impedimento para levantar el brazo altera las proporciones del cuerpo y reduce su estética, pues no se concibe que ese miembro deba permanecer en quietud. Por lo tanto, hay deformidad física, en sentido amplio aunque también pueda concurrir la perturbación funcional".
} 
dad, la de perder los ojos; en el segundo hay una corrosión generalizada en el rostro del sujeto pasivo y una pérdida de los ojos, por lo que la sanción, en virtud de la cláusula de absorción, es la pérdida anatómica, que a su vez castiga la deformidad causada por la pérdida de los ojos. El problema es protuberante y radica en que la cláusula no valora adecuadamente la corrosión generalizada en el rostro del sujeto pasivo, y obliga al operador judicial a no valorar adecuadamente el mayor desvalor de resultado del segundo ejemplo. Para este tipo de casos es preferible, sin lugar a dudas, concursar las lesiones efectivamente.

\section{Los agravantes específicos}

Al tenor de los artículos 119 y 120 cp las lesiones personales tanto en modalidad dolosa como culposa deberán remitirse a las agravantes propias del homicidio simple (art. 104 cP) y del homicidio culposo (art. $110 \mathrm{cP}$ ). Ahora bien, para efectos de este trabajo solo resultan relevantes las agravantes consagradas en los numerales 4, 6 y 7 del artículo 104 del cP. Esto se debe a que estas disposiciones tienen una especial importancia en el análisis dogmático jurídico del nuevo tipo penal, mientras que las restantes no representan mayor inconveniente en su aplicación.

\section{a) El artículo 119 del CP}

Además de hacer la remisión a las agravantes específicas del homicidio simple (art. 104 cP), el artículo 119 del CP contiene un agravante propio. Este agrava la pena cuando los sujetos pa- sivos de las lesiones personales dolosas sean menores de catorce (14) años, y podrá ser aplicado sin ningún obstáculo dado que no riñe sustancialmente con ninguna de las disposiciones legales consagradas en el artículo 104 cP.

\section{b) Numeral 4, artículo 104 CP: "Por precio, promesa remuneratoria, ánimo de lucro o motivo abyecto o fútil"}

La Corte Suprema de Justicia ha definido el motivo abyecto como el motivo despreciable, y el motivo fútil como aquel cuya importancia es insignificante o nimia (Sala de Casación Penal, 26 enero 2006). ${ }^{33}$ A nuestro juicio, un ataque con ácidos cuyo móvil sea, por ejemplo, el honor o el rechazo al acercamiento sexual tiene que ser considerado como un motivo fútil. Lo mismo sucedería en los eventos donde el sujeto activo actúa movido por celos y no hay un trastorno mental como la celopatía.

Ahora, ¿podría ser aplicado este agravante en los eventos donde el sujeto pasivo de un ataque con ácidos ataca, por venganza, a su victimario? Formalmente y a primera vista la respuesta es afirmativa. Desde luego, se aplicaría por el motivo abyecto y no por el motivo fútil. Lo cierto es que con independencia de la posición que se asuma, este agravante tendrá una aplicación

\footnotetext{
"Si de acuerdo con el Diccionario de la Lengua Española, abyecto es aquello despreciable, vil en extremo; y fútil aquello que carece de aprecio o importancia, es claro que el motivo aducido como desencadenante de la acción homicida se identifica plenamente con este último adjetivo, pues obrar por motivos fútiles no puede ser otra cosa que realizar el hecho delictivo por una causa tan insignificante, tan nimia, que hace resaltar en forma inmediata la falta de proporcionalidad entre el motivo y el hecho. Matar por vindicar la contestación, en los mismos términos, de un insulto que no provocó la víctima, es un acto acompañado de un motivo fútil, por lo insignificante" (sentencia proceso no. 22106. M. P.: Sigifredo Espinosa Pérez).
} 
muy casuística, atada al parecer del operador judicial y su concepción de lo que constituye o no un móvil extremadamente vil.

\section{c) Numeral 6, artículo 104 CP: "Con sevicia”}

La sevicia ha sido definida por la Corte Suprema de Justicia como una manifestación de especial perversidad o crueldad por parte del sujeto activo, que se materializa a través de la causación de padecimientos innecesarios e inhumanos a la víctima (sentencia de 21 de febrero de 1964). ${ }^{34}$ En consecuencia, determinar si hay o no sevicia dependerá de la modalidad comisiva de la lesión personal. Así, por ejemplo, en los casos donde el atacante vierta ácido en el rostro de la víctima de forma pura y simple no habría lugar para la sevicia puesto que dicha modalidad, por más inhumana e innecesaria que sea, corresponde al injusto penal contenido en el artículo 113 cr. Por lo tanto, esa acción está plenamente valorada por el nuevo tipo penal autónomo.

Diferente será el escenario si el sujeto activo, por ejemplo, colocando a la víctima en situación de indefensión (atándola) decide deformarla lentamente al verter una gota de ácido cada hora hasta que quede completamente irreconocible. El injusto penal, en esta modalidad, no

34 "Es frecuente confundir la sevicia con la repetición de los golpes, concepto que es absolutamente impropio porque lo que caracteriza tal circunstancia es el aumento del dolor en la víctima, fríamente provocado por el homicida y con el propósito cierto y definido de hacer sufrir al ofendido. Por ello cuando en la comisión de un homicidio el agente repite los golpes a su víctima bajo el primer impulso de cólera o de la ira, no hay sevicia, pues desde el punto de vista de la actividad del delincuente es como si se tratara de un solo golpe, porque los daños innecesarios no han sido causados de manera calculada y reflexiva. (...). La sevicia ha sido considerada como una manifestación de especial perversidad en el delincuente y en algunos casos como signo de anormalidad mental del homicida" (magistrado ponente: Julio Roncallo Acosta). quedaría plenamente valorado por el artículo 113 сP y debería ser agravado por el numeral 6 del artículo 104 del cP.

\section{d) Numeral 7, artículo 104 CP: “Colocando a la víctima en situación de indefensión o inferioridad o aprovechándose"}

La alevosía ha sido considerada por la Corte Suprema de Justicia como el modo traicionero o cobarde mediante el cual el sujeto activo asegura la comisión del delito sin un mayor riesgo para él. ${ }^{35}$ Sin lugar a dudas, en este agravante es donde yace uno de los mayores interrogantes sobre su aplicabilidad y es: ¿al aplicar este agravante no se estaría violentando el principio non bis in idem?

El principio del non bis in idem prohíbe que la misma conducta sea valorada y sancionada punitivamente de dos formas distintas. En consecuencia, por ejemplo, el non bis in idem se vería violentado al decir que un delito de rapto se debe sancionar penalmente concursando

35 De tiempo atrás, la jurisprudencia de esta Corporación ha señalado, en relación con el homicidio por alevosía a que hace alusión la agravante en comento, que este se produce cuando la conducta se comete "a traición, y en forma segura para el autor, de tal manera que la víctima esté en condiciones de indefensión o inferioridad" (sentencia de 25 de marzo de 1993, radicación 8844). "Todas las formas dolosas y cobardes de cometer homicidio y lesiones personales con un mínimo de peligro para el agresor, y un máximo de indefensión para la víctima, quedan comprendidas en la circunstancia calificante de la alevosía. Este vocablo tiene hoy en la doctrina un sentido amplísimo, equivalente a sorprender al ofendido descuidado e indefenso, para darle el golpe con conocimiento o apreciación, por parte del agente, de esas condiciones de impotencia en que se halla el sujeto pasivo del delito. La alevosía tiene, pues, un contenido objetivo y subjetivo, sin que sea de su esencia la premeditación. La dicha agravante se traduce generalmente en la ocultación moral y en la ocultación física. La primera, cuando el delincuente le simula a la víctima sentimientos amistosos que no existen o cuando le disimula un estado del alma rencoroso. La ocultación física, cuando se esconde a la vista del atacado, o se vale de las desfavorables circunstancias de desprevención en que se encuentra" (sentencia de 7 de febrero de 1955, p. 581). 
idealmente un constreñimiento ilegal (art. 182 СР) y un secuestro simple (art. $168 \mathrm{cP}$ ). Lo anterior, dado que el secuestro simple contiene en sí el desvalor propio del constreñimiento ilegal y por consiguiente concursarlo sería desvalorar doblemente el injusto penal.

Algo similar sucede en esta conducta. Si aceptamos (tal como se hizo al final del II.C.3.d) que el medio empleado en esta conducta implica un mayor desvalor de acción objetivo puesto que asegura ex ante el resultado material, correlativamente tenemos que reconocer que los medios empleados convierten este tipo de ataques en alevosos. La consecuencia práctica de esta interpretación es que, un ataque con ácidos que cause deformidad como secuela, por lo menos en principio, no podrá ser agravado por el numeral 7 del artículo 104 del cp, debido a que se estaría sancionando penalmente dos veces la misma acción, violentando el principio del non bis in idem.

\section{Los agravantes genéricos y los cuartos de movilidad punitiva}

En la parte especial del cP se encuentran consagradas las penas para cada delito, expresadas por un monto mínimo y por un monto máximo. Una vez identificado el monto mínimo y el monto máximo, el primero se le resta al segundo y se divide en cuatro. De la sustracción surge el ámbito de movilidad y de la división los cuartos punitivos.

Ahora bien, en cuanto al ámbito de movilidad el juez se encuentra limitado por las atenuantes y agravantes genéricas, por esta razón este se deberá atener a lo dispuesto en los artículos 61, 55 y 58 del cp, entre otros. Una vez determinado el cuarto al cual se circunscribe la sanción, el juez tiene una discrecionalidad más considerable, ya que puede imponer la pena que juzgue más adecuada dentro del cuarto de movilidad, acudiendo a las razones consagradas en el artículo 61 del cP.

Para efectos de este delito solo se estudiarán los numerales 3 y 4 del artículo 58 del cP, dado que son los que revisten mayor importancia.

a) Numeral 3, artículo 58 CP: “Que la ejecución de la conducta punible esté inspirada en móviles de intolerancia y discriminación referidos a la raza, la etnia, la ideología, la religión, o las creencias, sexo u orientación sexual o alguna enfermedad o minusvalía de la víctima"

Como se mencionó anteriormente, este agravante permite valorar adecuadamente la totalidad del desvalor de acción o de resultado en aquellos casos donde se presente algún tipo de discriminación, cualquiera sea su naturaleza. Afortunadamente, no se incluyó en el tipo autónomo una descripción típica que impidiera la aplicación de este tipo penal, puesto que le impediría al juez hacer una valoración ideal y global del injusto penal.

b) Numeral 4, artículo 58 CP: "emplear en la ejecución de la conducta medios de cuyo uso pueda resultar peligro común"

La Corte Suprema de Justicia ha estimado que la utilización de ácidos en disturbios o manifestaciones públicas genera peligro común y zozo- 
bra. ${ }^{36}$ Desde luego, el peligro común se deberá predicar de situaciones donde efectivamente exista tal amenaza para la seguridad pública y no podrá ser aplicado como una regla general. En otras palabras, no es plausible derivar de un ataque con ácido donde el sujeto pasivo se encuentra solitario, la creación de un peligro común o un riesgo jurídicamente desaprobado para el bien jurídico de la seguridad pública. El ácido no es un elemento que genera per se peligro común, pero la forma en que es empleado sí lo podrá generar y es en virtud de esto que se deberá aplicar o no la agravante genérica.

\section{CONCLUSIONES}

Después de hacer un análisis riguroso del tema es posible concluir, a partir del nuevo precepto legal, tres cosas. En primer lugar, la modificación legislativa tiene un alto grado de populismo punitivo. Esto se pudo observar tanto en los debates legislativos como en la misma reforma al Código Penitenciario. El legislador considera que este delito es la manifestación de una crueldad inusitada, de un daño irremediable y que, por lo tanto, debe ser castigado de forma ejemplar y diferencial a los otros tipos de deformidad. Objetivo que, indubitablemente, se consiguió puesto que los sujetos activos de los ataques con ácidos no obtendrán ninguno de los

36 "Los hechos que originaron la investigación son indudablemente idóneos para crear o estimular zozobra o terror, pues la pedrea en las calles aledañas a la Universidad, acompañada del empleo de ácidos y sustancias explosivas ocasionan la pérdida de sosiego y alteran el orden público y crean una atmósfera peligrosa, no solo para los atacados, en ese caso los agentes de la policía, sino para los particulares que se hallen en el lugar y para las personas y vehículos que circulan en sus inmediaciones" (sentencia de 20 de julio de 1988. Magistrado ponente: Jorge Carreño Luengas). beneficios sustitutivos de las penas. Ahora bien, este discurso ha generado una discriminación injustificada frente a los otros tipos de deformidad, lo cual es un despropósito. Adicionalmente, tras adoptar estas medidas el debate no ha acabado y, por el contrario, se ha desnaturalizado hasta tal punto que un sector importante de la política colombiana considera que debería ser imputado a título de tortura.

En segundo lugar, se introduce un tipo que valora el injusto desde la perspectiva de los medios empleados, en un sistema que únicamente se preocupaba por el resultado material. Esto, además de novedoso, es útil en cuanto garantiza una valoración exhaustiva del injusto penal. Así, pues, la modificación legislativa cobija y sanciona el desvalor de acción objetivo propio de esta modalidad criminal garantizando una plena valoración de la acción típica, antijurídica y culpable.

En tercer lugar, el legislador considera, acertadamente a nuestro juicio, que es posible causar un daño semejante a las consecuencias propias de las sustancias corrosivas. En este orden de ideas, por lo menos en términos punitivos, es posible que haya un resultado igual de grave causado con medios diferentes a los plasmados en la reforma legislativa y que obtenga una sanción semejante.

Al margen de lo anterior también se puede concluir que esta modificación tiene otras ventajas y desventajas. Dentro de las ventajas se encuentra que es posible identificar los casos en los cuales se presenta el delito en grado de tentativa y que, al no haber sido condicionado 
como un delito de género, es posible aplicar los agravantes propios de este tipo de móviles discriminatorios.

Por otra parte, dentro de las desventajas se encuentra que no es posible la aplicación del agravante número 7 del artículo 104 del cP, la no diferenciación entre secuelas transitorias y permanentes y la irrelevancia de la figura de la reparabilidad para esta.

Sin embargo, más allá de las ventajas o desventajas es imperativo indicar que el aumento del quantum punitivo difícilmente generará prevención general negativa. Además, es un despropósito que a menos de un año de haber creado un delito autónomo que sanciona las lesiones causadas con ácidos se esté discutiendo la posibilidad de imputar una tentativa de homicidio como regla general. Por último, consideramos que es imperativo replantear la necesidad y evaluar la idoneidad de la cláusula de absorción para aquellos tipos penales de lesiones personales que no se miden únicamente en virtud del resultado material sino por los medios empleados y que generan secuelas específicas y generalizadas en el cuerpo humano. En dichos casos resulta preferible concursar idealmente las lesiones personales causadas para garantizar una plena valoración del injusto penal.

\section{Referencias}

Álvarez García, F. (2011). Derecho penal español. Valencia: Tirant Lo Blanch.
Arboleda Vallejo, M. y Ruiz Salazar, J. (2012). Manual de derecho penal. Bogotá: Leyer.

Arenas, A. (1986). Comentarios al Código Penal colombiano. Bogotá: Editorial Temis.

Barrére Unzueta, M. (2009). Género, discriminación y violencia contra las mujeres. En Género, violencia y derecho. Buenos Aires: Editores del Puerto.

Brown, T., LeMay, E., Bursten, B. y Burdge J. (2004). Química, la ciencia central. México: Editorial Pearson.

Buompadre, J. (2009). Tratado de derecho penal. Buenos Aires: Editorial Astrea.

Bustos Ramírez, J. (2008). Derecho penal especial. Bogotá: Leyer.

Cámara de Representantes. (8 de mayo de 2012). Acta de Plenaria 122. Gaceta del Congreso, XXI(445).

Cardona Torres, J. (2010). Derecho penal. Parte especial. Barcelona: Bosch Casa S. A.

Castro Cuenca, C. (Coord.). (2011). Manual de derecho penal. Parte especial. Bogotá: Editorial Temis.

Congreso de la República. (21 de agosto de 2012). Informe de ponencia para primer debate al Proyecto de Ley 239 de 2012 Senado, 091 de 2011 Cámara. Gaceta del Congreso, XXI(536). 
Corte Constitucional. Sentencia C-022/96. M. P.: Carlos Gaviria Díaz.

Corte Constitucional. Sentencia T-572/99. M. P.: Fabio Morón Díaz.

Corte Constitucional. Sentencia T-881/02. M. P.: Eduardo Montealegre.

Corte Suprema de Justicia. Sentencia de 20 de septiembre de 1998. M. P.: Jorge Carreño Luengas.

Corte Suprema de Justicia. Sentencia de 21 de febrero de 1964. M. P.: Julio Roncallo Acosta.

Corte Suprema de Justicia. Sentencia de 25 de marzo de 1993. Radicado 8844.

Corte Suprema de Justicia. Sentencia de 5 de octubre de 2011. Radicado 33289. M. P.: María del Rosario González de Lemos.

Corte Suprema de Justicia. Sentencia de 7 de febrero de 1955. Gaceta Judicial, LXXIX.

Corte Suprema de Justicia. Sentencia proceso $n^{\circ}$. 22106, 26 de enero de 2006. M. P.: Sigifredo Espinosa Pérez.

De Silva de Alwis, R. (2010). Women Leading Change. A collection of essays from women leaders advancing justice in the Muslim world. Wellesley: Wellesley Center for Women, Wellesley College.

De Silva de Alwis, R. (2012). Domestica Violence Lawmaking in Asia: Some Innovative Trends in Feminist Lawmaking. Pacific Basin Law Journal, XXIX, 176-233.

Donna, E. A. (2008). Derecho Penal. (Tercera ed., t. 1). Buenos Aires: Rubinzal-Culzoni Editores.

Ferreira Delgado, F. J. (2006). Derecho penal especial. (t. 1). Bogotá: Editorial Temis.

Fiscalía General de la Nación. (7 de abril de 2014). Asegurado por agresión con ácido a Natalia Ponce de León. Obtenido de: http:// www.fiscalia.gov.co/colombia/noticias/asegurado-por-agresion-con-acido-a-natalia-ponce-de-leon/

Gómez Méndez, A. (1998). Delitos contra la vida y la integridad personal. Bogotá: Universidad Externado de Colombia.

Gómez Pavajeau, C. y Urbano Martínez, J. (2011). Lecciones de derecho penal. Bogotá: Universidad Externado de Colombia.

González Rus, J., Morillas Cueva, L., Peris Riera, J., Del Rosal Blasco, B. y Sainz-Cantero, J. (2011). Sistema de derecho penal español. Parte especial. Madrid: Dykinson, S. L.

Gutiérrez Anzola, J. (1952). Delitos contra la vida y la integridad personal. Bogotá: Universidad Nacional de Colombia.

Instituto Nacional de Medicina Legal y Ciencias Forenses. (Mayo, 2013). Violencia con agentes químicos. Anexo n. ${ }^{\circ} 1$. 
Instituto Nacional de Medicina Legal y Ciencias Forenses. Grupo Centro de Referencia Nacional sobre Violencia. Sistema de información para el análisis de la violencia y la accidentalidad en Colombia -SIAVAC.

Jescheck, H. y Weigend, T. (2002). Tratado de derecho penal. Parte general. Granada: Comares.

Marín, J. (2008). Derecho Penal. Buenos Aires: Hammurabi.

Mir Puig, S. (2007). Introducción a las bases del derecho penal. Buenos Aires: Editorial B de F.

Molina Fernández, F. (2010). Penal. Madrid: Ediciones Francis Lefebvre.

Naciones Unidas. (2009). Good practices in legislation on 'harmful practices' against women. Adis Abbeba, Etiopía: Autor.

Pabón Parra, P. (2013). Manual de derecho penal. Parte especial. Bogotá: Ediciones Doctrina y Ley.

Pacheco Osorio, P. (1972). Derecho penal especial. Bogotá: Editorial Temis.

Pérez, L. (1991). Derecho penal. Bogotá: Editorial Temis.

Posada Maya, R. (2008). Temas de derecho penal. Bogotá: Ediciones Uniandes y Editorial Temis.
Posada Maya. R. (2012). Delito continuado y concurso de delitos. [Reimpresión]. Bogotá: Grupo Editorial Ibáñez y Universidad de los Andes.

Romeo Casabona, C. (2004). Los delitos contra la vida y la integridad personal y los relativos a la manipulación genética. Granada: Editorial Comares.

Roxin, C. (2013). El concepto de bien jurídico como instrumento de crítica legislativa sometido a examen. Revista Electrónica de Ciencia Penal y Criminología, 1-27.

Semana.com. (10 de abril de 2014). Ataques con ácido son típicos casos de tortura. Obtenido de: http://www.semana.com/nacion/ articulo/ataques-con-acido-son-tipicos-casos-de-tortura-procurador/383243-3

Semana.com. (9 de abril de 2014). Presentan proyectos de ley para endurecer penas contra atacantes con ácido. Obtenido de: http:// www.semana.com/nacion/articulo/presentan-proyectos-de-ley-para-endurecer-penascontra-atacantes-con-acido/383201-3

Shah, H. (2009). Brutality by acid: Utilizing Bangladesh as a model to fight acid violence in Pakistan. Winsconsin International Law Journal, XXVI (4).

Suárez-Mira, C. (2011). Manual de derecho penal. Pamplona, España: Thomson Reuters.

Taylor, L. M. (2001). Saving the face: Acid attack laws after U.N. convention on the elimination 
of all forms of discrimination against women. Velásquez, F. (2013a). Delitos contra la vida y la Georgia Journal of International of Comparaintegridad personal. Bogotá: Ediciones Juríditive Law. cas Andrés Morales.

Tócora, L. (2009). Derecho penal especial. Bo- Velásquez, F. (2013b). Manual de derecho pegotá: Librería Ediciones del Profesional Ltda. $\quad$ nal, parte general. Bogotá: Ediciones Jurídicas Andrés Morales. 